Research Paper

\title{
Mechanical deterioration of rock salt at different confinement levels: A grain-based lattice scheme assessment
}

\author{
Ning Liu ${ }^{a}$, Min $\mathrm{Li}^{\mathrm{a}}$, Weimin Chen ${ }^{\mathrm{b}, *}$ \\ ${ }^{a}$ School of Aeronautics Sciences and Engineering, Beijing University of Aeronautics and Astronautics, Beijing 100191, China \\ ${ }^{\mathrm{b}}$ Key Laboratory for Mechanics in Fluid Solid Coupling System, Institute of Mechanics, Chinese Academy of Sciences, Beijing 100190, China
}

\section{A R T I C L E I N F O}

\section{Article history:}

Received 23 August 2016

Received in revised form 1 December 2016

Accepted 5 December 2016

Available online 18 December 2016

\section{Keywords:}

Crystalline grain

Lattice scheme

Smooth joint logic (SJL)

Confining pressure

Mechanical deterioration

\begin{abstract}
A B S T R A C T
A two-dimensional gain-based lattice approach, is developed here, driven by the needs for modelling strategy of rock salt (halite). In this scheme, considering crystalline micro-structure, halite is discretized into polygonal grains by smooth joint logic, in which mass nodes with micro-rotation are connected by springs. The contacts between grains are in a point-to-point manner, which can avoid complex contact definition (point-to-edge, or edge to edge, etc.) in classical numerical simulations. Breakage and creation of interactions in dynamic spring network is applied to implement the dislocation and diffusion within grains in addition to crystal plasticity.

Brazilian tensile test, unconfined and triaxial compression tests are presented for a guideline of parameter identification and a consistent simulation set-up. Relatively comparable results including brittleductile transition could be reproduced, revealing the potential to study and quantify the interplays of mechanical deterioration of halite.
\end{abstract}

(c) 2016 Published by Elsevier Ltd.

\section{Introduction}

Rock salt is also known as halite, which is a kind of salt and exhibits isometric crystal structure. It was found to have a low permeability and porosity [1,2], excellent sealing capacity of faults [3] and possess a creep behaviour under a low stress level [2]. Due to those incredible characteristics, rock salt has been widely used in many fields. For instance, early engineering studies of rock salt were driven largely by the need to design safe salt mines [2]. Then, it was applied into oil or hydrocarbon gas storage [4], and even it was considered to have the possibility to host a deep geological repository for radioactive, high-level waste from nuclear facilities [5], such as Waste Isolation Pilot Plant of USA [6]. Based on the economic and environment-friendly importance, in order to provide a scientific basis for proper stability evaluation and safe design, construction and operation, it's necessary for us to study deeply on halite rocks.

In recent decades, scholars and researchers have made a lot of efforts from the perspectives of experimental tests, theoretical analysis and numerical simulation, which have influenced positively on current research and future potential applications. Experimental measurement is a kind of direct methodology. Some static

\footnotetext{
* Corresponding author.

E-mail address: wmchen@imech.ac.cn (W. Chen).
}

and dynamic material parameters of rock salt specimens were obtained by this method [7-11]. Time [2,12,13] and temperature $[14,15]$ dependent properties were observed and studied in the past. As for the aspect of theoretical studies, some mathematical models and contact laws were developed based on the in-situ measurements and laboratory tests to predict short-term as well as long-term mechanical responses [16-19]. Nevertheless, numerical simulation may be regarded as a bridge between theoretical methods and experiments. It could provide valuable reference data and prediction for engineering design or practical applications in a more economic and efficient way. Additionally, it may complete some experiments which are hard or even impossible to cope with by other approaches [20]. With the great improvement of computer performance, numerical methods are playing an increasingly important role in the current research. For salt-rock, exploration of advisable constitutive models and modelling strategy is still an ongoing task [21].

Generally, the numerical simulations could be further divided into two categories: continuum and dis-continuum based methods. Within continuum researches, as early as 1989, Evans and Nunn [22] used the finite difference method (FDM) assessed the driving convection mechanisms near salt dome [22]; In 1998, FDM was used to model the development of the salt structure [23]. Also, finite element method (FEM) has been applied to study the mechanical properties of rock salt. For example, in 1972, based 
on FEM, Thoms et al. [24] tried to model the creep behaviour of rock-salt pillar samples for predicting the closure of rooms in salt domes or bedded salt [24]; recently, Moghadam et al. [25] utilized elasto-visco-plastic constitutive model into FEM equations to explore the dilatancy, short- and long- term failure of rock salt. While, due to the limitations of the continuum assumptions, these methods may barely handle some problems related to large-scale fractures, complex discontinuities, or microscopic mechanism [26].

Therefore, the dis-continuum based methods, like molecular dynamics (MD) and discrete element method (DEM), were developed. MD, whose basic elements are actual ions, atoms and molecules, mainly deals with the problems at micro- or nano- scale. This scale feature and complex potential functions may limit its research and engineering applications. Based on the initial concept of MD, DEM was first proposed by Cundall [27] to study rocks and other geo-materials. Early, it used bonded particle model, consisting of circular or spherical elements [28], to simulate grains. Obviously, these rounded shape particles are not proper candidates for rock salt simulation, based on halite's physical and chemical micro-structure. For now, polygonal-shaped elements in twodimensional or three-dimensional have been developed and widely used in the salt-rock study $[29,30]$. These means could be utilized to capture the inter-crystalline deformation and failure behaviours of rock salt, but it seems to be difficult to simulate the micro-cracks opening, propagation and proliferation within crystalline gains. Besides, the implementation of those methods are so complex that it may highly penalize calculation efficiency [28].

Meanwhile, the concept of lattice models (LM) was established. In theory, lattice models are based on the atomic lattice models of materials [31]. In contrast to DEM, the elements are replaced by point masses instead of spherical particles and the contacts between elements by simple springs or beams. These characteristics make LM flexible to model both granular media and continuum systems [31]. The scale of specimens in research may be extended by a coarser lattice idea (larger than real atomic scale) that could be dated back to Hrennikoff [32]. This model is well suitable to emulate the fractures in rock and other engineering materials. However, it seems to be hard to simulate the cracking or sliding along the grain boundaries, which exactly exist in rock salt.

Based on the physical and chemical nature of salt-rock, a grainbased lattice scheme is developed here, that might be regarded as a kind of granular media with polyhedral elements incorporating micro-rotation and breakage/creation of interactions within crystalline grains. The whole sample is discretized into nodes with given masses connected by normal and shear springs with MohrCoulomb criterion. Some points of departure from the available lattice models are the introduction of given micro-rotational inertia independent of lattice spacing, smooth joint logic (SJL) and creation of new interactions. They could be used to control the sizedependent effect, capture grain sliding and implement the dislocation and diffusion within grains in addition to crystal plasticity, respectively.

The aim of this research is to attempt to establish an alternative and promising modelling strategy for rock salt at grain scale in a more realistic and simpler way. A guideline for parameter identification and a consistent simulation procedure is presented. Complementary insights and a deeper understanding of confinement effect on mechanical deterioration are explored systematically and quantitatively from the perspectives of compressive strength, volume changes, fabric tensors and failure modes. The rest of this paper is organized as follows. Firstly, basic methods we used are described in Section 2, including the general idea of lattice approach, a review of the concept of SJL, parameter identification and the calculation process. Then, numerical simulations and results are presented in Section 3 compared with experiments to validate the model and calibrate material parameters by Brazilian tension and uniaxial compression simulations, explore the confining pressure effect by varying confinement levels in biaxial compression tests; also, the capability in predicting mechanical behaviour of rock salt is discussed and evaluated. Finally, some conclusions are highlighted in Section 4.

\section{Basic methods}

Previously, lattice model was mainly used to model elastic and brittle media [33]. While, some researches show it has the potential to emulate ductile materials $[34,35]$ as well. Therefore, we extend it to represent a kind of cohesive-frictional medium, including brittle-to-ductile transition, rock salt. Lattice networks stand for the interior of crystalline grains, and the SJL accounts for the movements along grain boundaries. The interactions between polygonal grains generated by PolyMesher code [36] are in a simple point-to-point manner, which may take less time consuming than that polyhedral interaction logic in DEM [37]. In particular, the singularity issues involved in the definition of those complex contacts, such as the interactions among facets, edges and points [38], could be avoid [39].

\subsection{Interactions in lattice model}

A cohesive frictional constitutive law [28] is used to define the interactions between two nodes. This model takes the linear elastic behaviour into consideration, with cohesion and friction, and Mohr-Coulomb plasticity surface is also included.

Under the condition of a small deformation, rock salt behaves elastically and linearly. During that process, contact forces, including normal force $F_{\mathrm{n}}$ and tangential force $F_{\mathrm{s}}$, for every pair of interaction, are applied here, and the contact model is shown as Fig. 1. Normal force $F_{\mathrm{n}}$ between two nodes, can be written as

$F_{\mathrm{n}}=k_{\mathrm{n}} \cdot \Delta d$,

$\Delta d=d_{\mathrm{eq}}-d$,

$d=\left(\vec{x}_{2}-\vec{x}_{1}\right) \vec{l}_{12}$

where $k_{\mathrm{n}}, d_{\mathrm{eq}}, d, \vec{x}_{1}, \vec{x}_{2}, \vec{l}_{12}$ is the normal spring stiffness and the equilibrium distance, the distance, coordinate vectors and the normal of the spring between two nodes as shown in Fig. 2, respectively.

In the case of tension, we define a maximum acceptable tensile

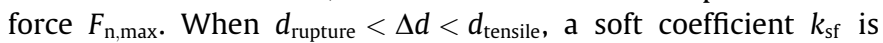
introduced, and then the tensile force $F_{\mathrm{n}}$ can be displayed as
Normal Force

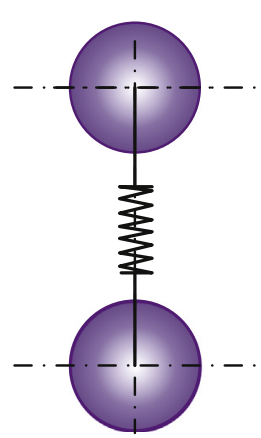

Tangential Force

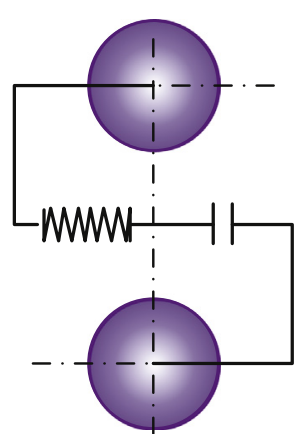

Fig. 1. Constitutive model (including Mohr-Coulomb criterion). 

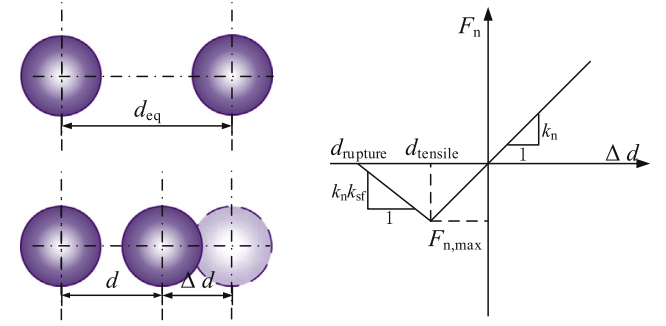

Fig. 2. Normal force between two nodes.

$F_{\mathrm{n}}=-k_{\mathrm{n}} \cdot k_{\mathrm{sf}} \cdot\left(\Delta d-d_{\text {rupture }}\right)$,

$d_{\text {rupture }}=d_{\text {tensile }}-\frac{F_{\mathrm{n}, \max }}{k_{\mathrm{n}} \cdot k_{\mathrm{sf}}}$,

$d_{\text {tensile }}=-\frac{F_{\mathrm{n}, \max }}{k_{\mathrm{n}}}$.

The normal force is set to zero, after the value of relative distance $\Delta d$ is smaller than $d_{\text {rupture, namely the springs between two nodes }}$ are removed.

For tangential force $F_{\mathrm{s}}$ smaller than a maximum shear force $F_{\mathrm{s}, \max }$ (Fig. 3) calculated from the Mohr-Coulomb criterion, we use the expression,

$F_{\mathrm{s}}=k_{\mathrm{s}} \cdot \Delta u_{\mathrm{s}} \quad\left(F_{\mathrm{s}} \leqslant F_{\mathrm{s}, \max }\right)$,

$F_{\mathrm{s}, \max }=F_{\mathrm{c}}+F_{\mathrm{n}} \tan \varphi_{\mathrm{b}}$,

where $\Delta u_{\mathrm{s}}, k_{\mathrm{s}}, F_{\mathrm{c}}$ and $\varphi_{\mathrm{b}}$ is shear displacement increment in the last time step, the shear spring stiffness, cohesive force and local frictional angle, respectively. It leads to the micro-rotation of the elements, due to the included shear force.

When the tangential force $F_{\mathrm{s}}$ exceeds its corresponding maximum tangential force $F_{\mathrm{s} \text {, max }}$, shear rupture occurs, and then the maximum shear force $F_{\mathrm{s}, \max }$ drops to another value $\left\{F_{\mathrm{s}, \max }\right\}_{\text {new }}$ for new created frictional interactions obtained by

$\left\{F_{\mathrm{s}, \text { max }}\right\}_{\text {new }}=F_{\mathrm{n}} \tan \varphi_{\mathrm{c}}$,

where $\varphi_{\mathrm{c}}$ is the local residual frictional angle.

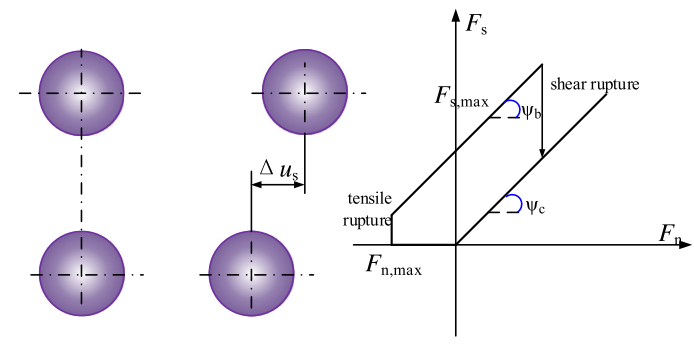

Fig. 3. Tangential force between two nodes.

\subsection{Smooth joint logic (SJL)}

The smooth joint logic (SJL) is based on the development of the Synthetic Rock Mass model [40]. Originally, it was used to simulate the pre-existing cracks and faults in DEM samples [29,41-43] as shown in Fig. 4. While, in this paper, we apply it to the simulation of the movements along grain boundaries inside of rock salt, namely crystalline structure. The forces acting on the nodes crossing the joints use the similar expressions described in Section 2.1. Fig. 4 shows the differences between elements contact orientation and movements induced by shearing with and without SJL using DEM. The elements on either side of the discontinuity plane (yellow) are distinguished by different colours, blue and purple, and the green ones represent the DEs consisting of the matrix. Fig. 4 (c) and (d) exhibit the movement trajectories of one DE around the other one, whose interaction is across the pre-existing crack in classical contact orientation and modified contact orientation that is perpendicular to the normal of the joint, respectively. In order to show the difference clearly, in these figures, only the movements between two elements of one interaction crossing the plate are considered, and one of the elements is assumed to be fixed, while actually is supposed to move to the opposite direction.

Therefore, some diminutive modifications are necessary for the interactions crossing the discontinuities. In general, the direction vector of contact between two nodes is given by

$\vec{l}_{12}=\frac{\vec{x}_{2}-\vec{x}_{1}}{\left\|\vec{x}_{2}-\vec{x}_{1}\right\|}$

The modified contact normal is collinear with that of the surface $\vec{n}_{\mathrm{j}}$, so the definition of $d$ in Eq. (2) should be adjusted as well, shown as follows,

$d=\left(\vec{x}_{2}-\vec{x}_{1}\right) \vec{n}_{\mathrm{j}}$

when the dilatation due to sliding occurs, $d$ is written as

$d=\left(\vec{x}_{2}-\vec{x}_{1}\right) \vec{n}_{\mathrm{j}}+\Delta u_{\mathrm{s}} \tan \psi$

where $\psi$ is the dilatation angle from the input parameters. Fig. 5 depicts the SJL inserted in this lattice model. The interactions between two polygonal grains are in simple point-to-point way, which may eliminate the extensive time-consuming from the polyhedral interaction logic [37].

\subsection{Parameter identification}

Material parameter identification can be treated as an inverse problem, which is a key step in numerical simulations. Here, a NL2SOL algorithm in Dakota analysis toolkit [44] is applied to a)

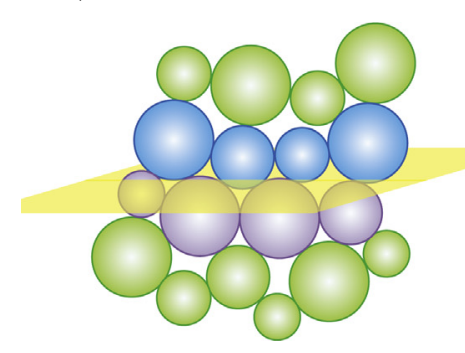

b) c)

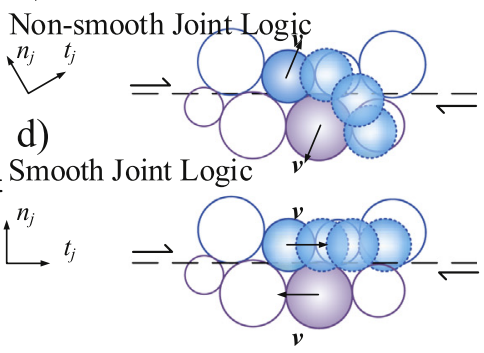

Fig. 4. DEM-DFN model (a); DEs on the either side of the discontinuity plane (b); the movements without and with SJL of one DE (c), (d). 


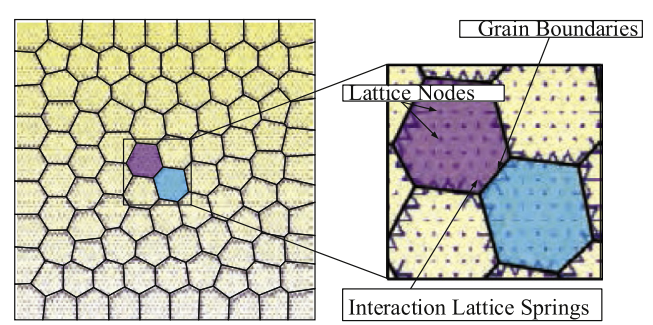

Fig. 5. Visualization of grain-based lattice model in two dimensions.

obtain optimal solutions that minimize a sum of the squares residuals (the relative errors between the simulation model and the given data) shown as below [44],

$R(\mathbf{x})=\sum_{i=1}^{N}\left(\frac{a_{i}(\mathbf{x})-a_{0}}{a_{0}}\right)^{2}+\sum_{i=1}^{N}\left(\frac{b_{i}(\mathbf{x})-b_{0}}{b_{0}}\right)^{2}+\ldots$,

$\mathbf{X}_{\text {Lower }} \leqslant \mathbf{X} \leqslant \mathbf{X}_{\text {Upper }}$,

in which $\mathbf{x}$ is an n-dimensional vector of input parameters and $\mathbf{x}_{\text {Lower }}$ and $\mathbf{x}_{\mathrm{Upper}}$ are the lower and upper bounds, respectively; $a_{i}(\mathbf{x})$ and $b_{i}(\mathbf{x})$ are the simulation data; $a_{0}$ and $b_{0}$ are corresponding experimental data; $N$ is the number of objective data for calibration.

In order to reduce the iterations, reasonable initial guess values and the lower and upper bounds should be chosen. The relations between springs' parameters and macroscopic material constants can be obtained, based on the conservation law of strain energy described as follows [31],

$U_{\text {cell }}=U_{\text {continuum }}$,

where $U_{\text {cell }}$ is the energy of lattice unit cells, and $U_{\text {continuum }}$ is the equivalent value in continuum concept. Then the elastic modulus is estimated from the following expression:

$C_{i j n m}=\frac{\partial^{2} U_{\text {cell }}}{\partial \varepsilon_{i j} \partial \varepsilon_{n m}}$.

The order of $C_{i j n m}$ is reduced from fourth to second one by the Voigt notation, and become [31]

$\mathbf{C}=\frac{1}{8 \alpha^{2 \mathrm{D}}}\left(\begin{array}{ccc}3 k_{\mathrm{n}}+k_{\mathrm{s}} & k_{\mathrm{n}}-k_{\mathrm{s}} & 0 \\ k_{\mathrm{n}}-k_{\mathrm{s}} & 3 k_{\mathrm{n}}+k_{\mathrm{s}} & 0 \\ 0 & 0 & k_{\mathrm{n}}+k_{\mathrm{s}}\end{array}\right)$

in which $\alpha^{2 \mathrm{D}}=\frac{\sum_{i}^{N_{i}}\left(l^{2}\right)^{i}}{A t}$, and $l, A$ and $t$ is the length of springs, the area and the thickness of the sample, respectively. Then, the macroscopic elastic parameters can be described as

$$
\begin{aligned}
& k_{\mathrm{n}}=\frac{2 E}{\alpha^{2 \mathrm{D}}(1-v)}, \\
& k_{\mathrm{s}}=\frac{2(1-3 v) E}{\alpha^{2 \mathrm{D}}\left(1-v^{2}\right)} ; \\
& v=\frac{k_{\mathrm{n}}-k_{\mathrm{s}}}{3 k_{\mathrm{n}}+k_{\mathrm{s}}} \\
& E=\frac{k_{\mathrm{n}} \alpha^{2 \mathrm{D}}}{2}\left(1-\frac{k_{\mathrm{n}}-k_{\mathrm{s}}}{3 k_{\mathrm{n}}+k_{\mathrm{s}}}\right) .
\end{aligned}
$$

We set the initial values and bounds of elastic constants according to the relations. After multiple iterations, the "best" values under given objective functions will be approached.

\subsection{Calculation process}

At first, the coordinates of the lattice mass nodes are generated within every polygon. Secondly, the nodes are connected by nor- mal and shear springs in pre-determined way that is different from the bonded-particle model [45]. Then the movement orientations of nodes crossing the grain boundaries are modified according to the discontinuity planes' normal. The forces and moments acting on every node are calculated. According to a central difference scheme, the motion of nodes [37] is computed as follows,

$$
\begin{aligned}
& \dot{d}_{i}^{\left(t+\frac{\Delta t}{2}\right)}=\dot{d}_{i}^{\left(t-\frac{\Delta t}{2}\right)}+\frac{\sum F_{i}^{(t)} \Delta t}{m}, d_{i}^{(t+\Delta t)}=d_{i}^{(t)}+\dot{d}_{i}^{\left(t+\frac{\Delta t}{2}\right)} \Delta t ; \\
& \omega_{i}^{\left(t+\frac{\Delta t}{2}\right)}=\omega_{i}^{\left(t-\frac{\Delta t}{2}\right)}+\frac{\sum M_{i}^{(t)} \Delta t}{I}, \\
& \theta_{i}^{(t+\Delta t)}=\theta_{i}^{(t)}+\omega_{i}^{\left(t+\frac{\Delta t}{2}\right)} \Delta t,
\end{aligned}
$$

where $I$ is the given micro-rotation inertia that is independent of $l$ and from inputs to quantify size-dependent effect. In order to get quasi-static solutions, a non-viscous damping is utilized to dissipate kinetic energy $[46,47]$. The damped force $\Delta F_{\text {damped }}$ of node $i$ may be written as follows,

$\frac{(\Delta F)_{\text {damped }}^{i}}{F_{i}}=-\xi \cdot \operatorname{sgn}\left(\dot{d}_{i}^{\left(t-\frac{\Delta t}{2}\right)}+\frac{\ddot{d}_{i} \cdot \Delta t}{2}\right)$.

After updated position of every node is set, if new frictional interaction is created or not will be determined by searching for neighbours. Then, the forces acting on every spring are calculated from the relative displacements of the nodes by the relations described in Sections 2.1 and 2.2. After the nodal forces are reset, whether new cracks occur will be detected. Spring networks will be updated on every time step according to the detection. The flowchart of the whole calculation process is illustrated in Fig. 6.

\section{Simulations and discussions}

For simplicity, we emulate a halite sample in two dimensions (2D) with a high-resolution (at least 80 nodes across its smallest dimension) to reduce the mesh sensitivity [48] and minimize the anisotropy caused by lattice orientation. Firstly, it's necessary to calibrate the mechanical properties of this 2D lattice model. This part is mainly accomplished by solving inverse problems from Brazilian tension and uniaxial compression tests using the materials properties $[8,49-51]$ listed in Table 1 . From that table, we can see the material parameters of rock salts vary in a large range and halite rocks bear tension considerably worse than compression [52]. The ratio of the compressive strength versus tensile strength can be more than 20 . This calibration procedure will verify the correction of this algorithm by comparing with the failure modes and data from experimental tests. Besides, the uni-axial compression test results may help to predict where the transition from brittle failure mode to ductile one will appear, which plays an important role in confinement effect issues. Then, according to the prediction, several biaxial compression tests, the counterparts of triaxial compression tests in 3D, are conducted. The key topics in confining pressure effect on mechanical deterioration of rock salt are discussed based on the numerical results. It's worth mentioning that, in this paper, we are trying to study the short-term mechanical properties of halite. That means the viscous damping and temperature dependence involved in creep behaviour is beyond the scope of this research.

\subsection{Calibration procedure}

The input parameters of rock salt include elastic parts and plastic ones. To accelerate calibration process, some reasonable assumptions are applied here. Mass nodes representing the matrix and the grain boundaries share some same inputs, like $k_{\mathrm{n}}, k_{\mathrm{s}}, m, I$ and $F_{\mathrm{c}}$. Also, they have some different parameters, i.e. $\varphi_{\mathrm{b}}$ and only 


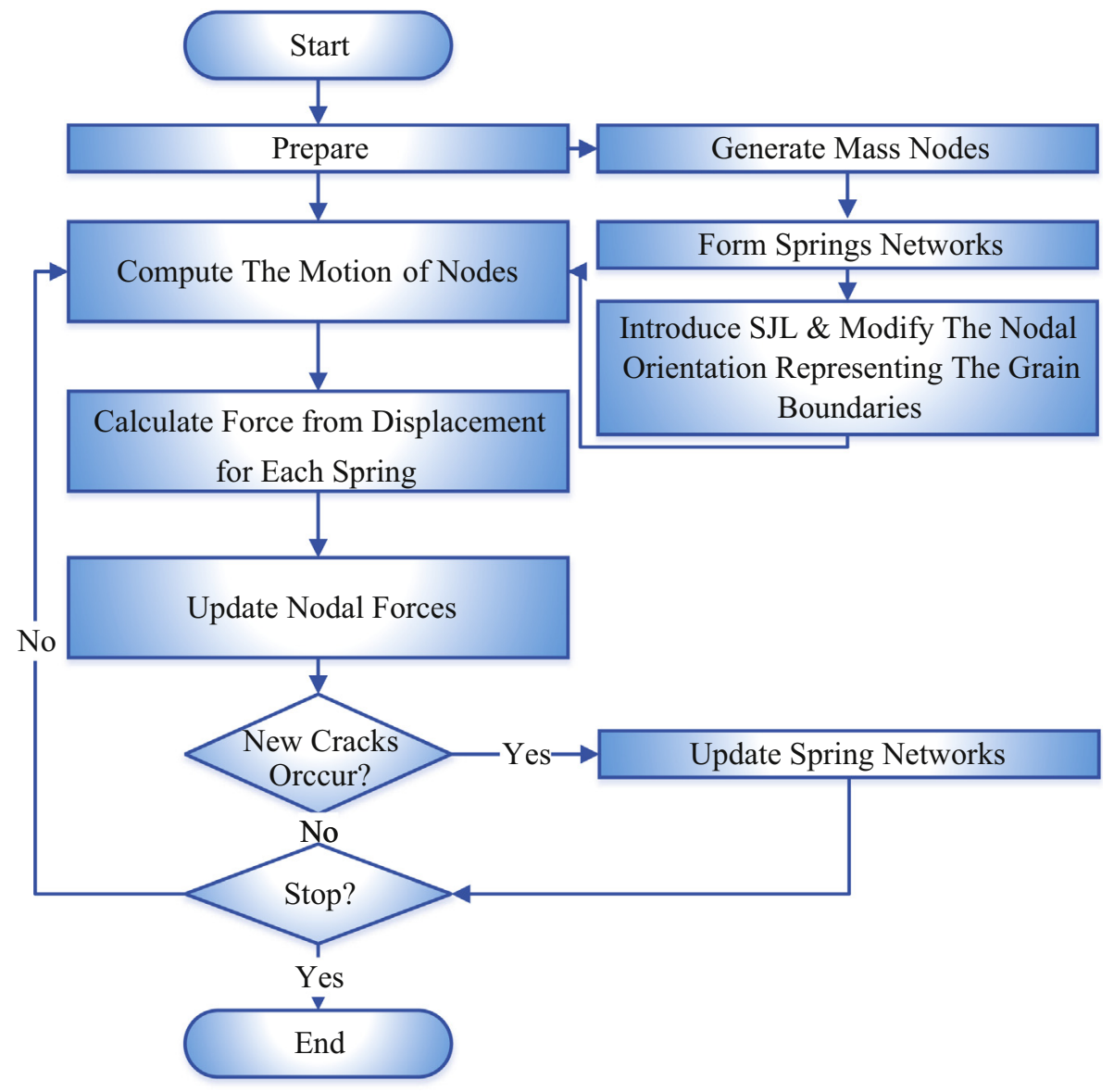

Fig. 6. Flowchart of this grain-based lattice scheme with SJL.

Table 1

Macroscopic mechanical properties of rock salt.

\begin{tabular}{ll}
\hline Material parameters & Values \\
\hline Young's modulus $E(\mathrm{GPa})$ & $25.65 \pm 6.65[7] ;$ \\
& $5.15 \pm 0.75[49] ;$ \\
Poisson's ratio $v$ & $25.2 \pm 1.9[51]$ \\
& $0.28 \pm 0.11[7] ;$ \\
Uniaxial compressive strength $\sigma_{\mathrm{UCS}}(\mathrm{MPa})$ & $0.31[49] ;$ \\
& $0.37 \pm 0.11[51]$ \\
\multirow{2}{*}{ Brazilian tensile strength $\sigma_{\mathrm{BTS}}(\mathrm{MPa})$} & $28.9 \pm 3.6[7] ;$ \\
& $18.67 \pm 1.61[49] ;$ \\
\end{tabular}

along the grain boundaries does dilation angle and tensile failure exist [30]. The optimal parameters of the inputs could be attained by minimizing the values of Eq. (16) by iterations.

\subsubsection{Basic elastic parameters}

In this part, basic elastic parameters, $k_{\mathrm{n}}, k_{\mathrm{s}}, I$, are chosen by compression tests without micro-cracks $\left(F_{\mathrm{c}}\right.$ and $F_{\mathrm{n} \text {,max }}$ are extremely large). Then, objective functions in NL2SOL algorithm takes the formation as follows,

$R_{1}\left(\mathbf{x}_{1}\right)=\sum_{i=1}^{N}\left(\frac{\left(-\frac{\varepsilon_{x x}}{\varepsilon_{y y}}\right)_{i}\left(\mathbf{x}_{1}\right)-v}{v}\right)^{2}$

$\mathbf{x}_{1}=\left(\begin{array}{lll}k_{\mathrm{n}} & k_{\mathrm{s}} & I\end{array}\right)$, where $\varepsilon_{x x}, \varepsilon_{y y}$ and $v$ are transverse and axial strain from lattice simulations, and target poisson ratio, respectively. The initial guess of normal and shear stiffness of springs could be estimated from Eq. (13), based on the Young's modulus and Poisson's ratio from experimental tests [49]. After getting the "best" values, the fitted slope of the axial-force to axial-strain curve could be written as,

$k=S_{\text {cross }} \cdot E$,

where $E$ is the target Young's modulus and $S_{\text {cross }}$ is constructed cross-section area. Every node is given the mass by,

$m=\frac{\rho H_{2 \mathrm{D}} S_{\text {cross }}}{N_{\text {nodes }}}$,

in which $\rho, H_{2 \mathrm{D}}$ and $N_{\text {nodes }}$ are target density, height of twodimensional sample and the nodes number, respectively.

\subsubsection{Plastic tension parameters}

The plastic parts of inputs in tension cut-off conditions, such as the maximum tensile force of the springs crossing the grain boundaries $F_{\mathrm{n} \text {,max }}$ and the soft coefficient $k_{\mathrm{sf}}$, can be gotten by the Brazilian tension tests. Widely, the Brazilian test is used for indirect measurement of tensile strength of rocks and other materials. The tensile strength can be back calculated by

$\sigma_{\mathrm{BTS}}=\frac{2 P}{\pi D t}$,

where $P, D, t$ is the applied load, diameter and thickness of the sample. The average grain size of rock salt is about 3-5 $\mathrm{mm} \mathrm{[12]} \mathrm{and} \mathrm{the}$ specimen diameter in this kind of test shall preferably be at least 10 times of the grain size [53]. Therefore, this numerical test is 


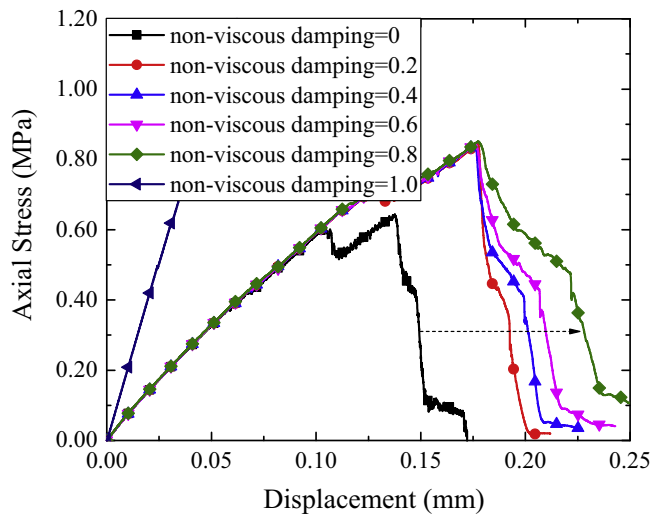

Fig. 7. The axial stress to vertical displacement curves of Brazilian tests with different damping.

performed on a circle disc with the diameter of $40 \mathrm{~mm}$, consisting of 79 polygons with a mean size of $4 \mathrm{~mm}$.

As aforementioned, the non-viscous damping and strain rate may influence the numerical results, so a reasonable damping and rate should be chosen at first. Fig. 7 recapitulates the various response curves of different numerical damping, from 0 to 1.0. Accompanied with the same other parameters, the tensile strength, Young's modulus and strain at the failure peak increase with the damping. It can be seen from Fig. 8 that strain rate poses a greater effect on the mechanical behaviours with respect to increasing damping value. Consequently, 0.2 seems to be an ideal numerical damping value for this model.

Based on these tests, optimization values of $F_{\mathrm{n}, \max }$ and $k_{\mathrm{sf}}$ are calculated to fit the macroscopic mechanical properties of rock salt using the objective function,

$$
R_{2}\left(\mathbf{x}_{2}\right)=\sum_{i=1}^{N}\left(\frac{(\sigma)_{i}\left(\mathbf{x}_{2}\right)-\sigma_{0}}{\sigma_{0}}\right)^{2}
$$

$\mathbf{x}_{\mathbf{2}}=\left(\begin{array}{ll}F_{\mathrm{n}, \max } & k_{\mathrm{sf}}\end{array}\right)$.

As illustrated in Fig. 9(c), cracks accumulate along the grain boundaries and failure surface is nearly parallel to the loading direction. That deterioration mode and stress-displacement tendency agree with the results [50] from laboratory measurements (Figs. 9 and 10).

\subsubsection{Plastic shear parameters}

Substituting available inputs, a series of uni-axial compression tests are continued for the inelastic shear parameters in MohrCoulomb criterion. The tests are performed on a rectangle specimen with a width of $40 \mathrm{~mm}$ and a length of $80 \mathrm{~mm}$, including 184 polygonal grains with average grain size of $4 \mathrm{~mm}$. Load is applied through displacement boundary conditions, moving the upper nodes equally and slowly. Fig. 11 summarizes the strain rate effect on mechanical properties tests with the non-viscous damping of 0.2: the vertical axis is signaled as "ratio" standing for the parameters versus reference values at strain rate equal to $0.50 \mu \mathrm{m} / \mathrm{s}$. Young's modulus/Poisson's rate increases/decreases

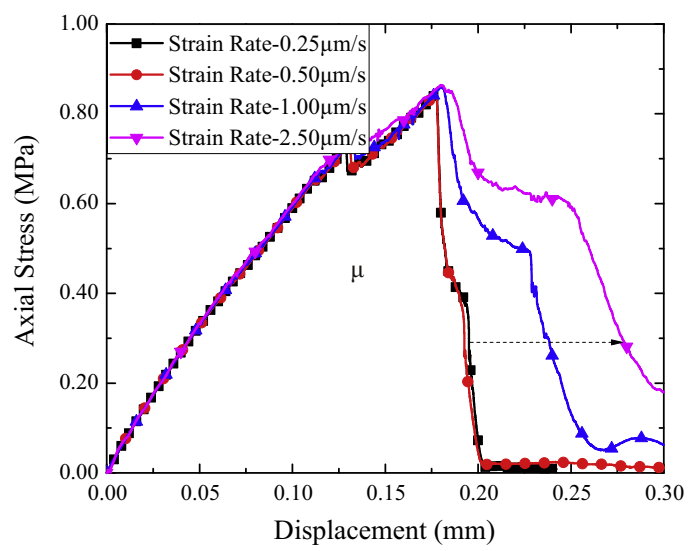

(a) Non-viscous damping $=0.2$.

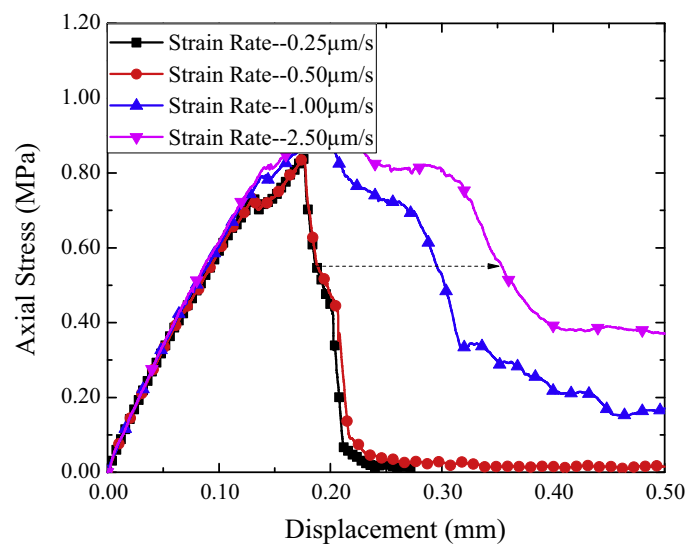

(c) Non-viscous damping $=0.6$.

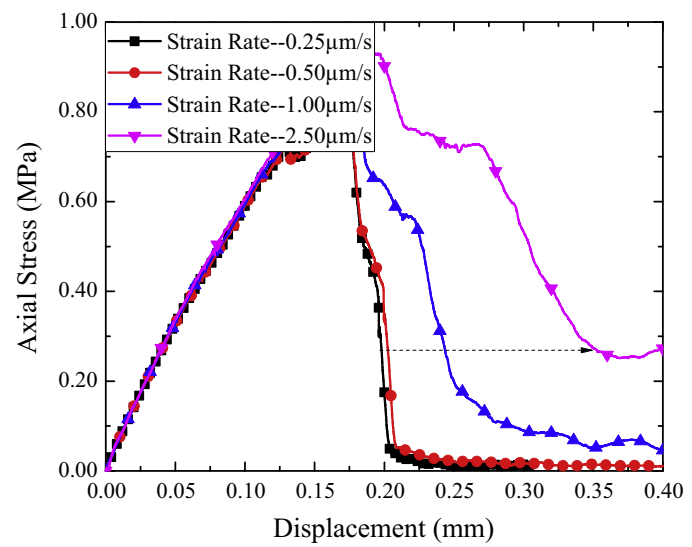

(b) Non-viscous damping $=0.4$.

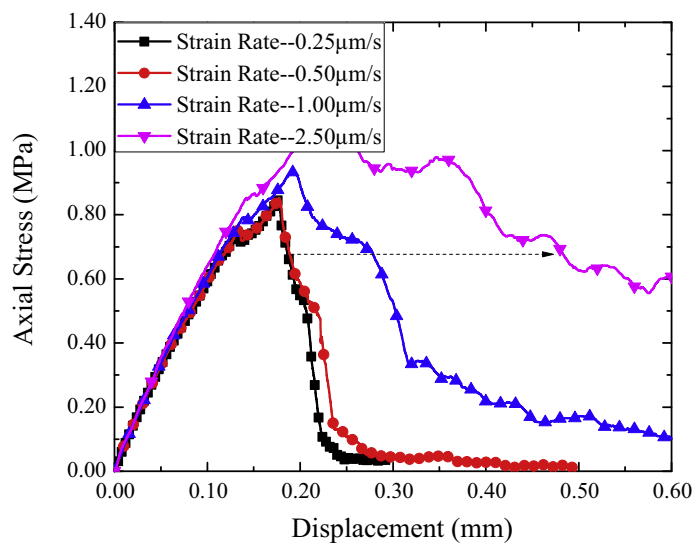

(d) Non-viscous damping $=0.8$.

Fig. 8. Strain rate effect at different non-viscous damping. 


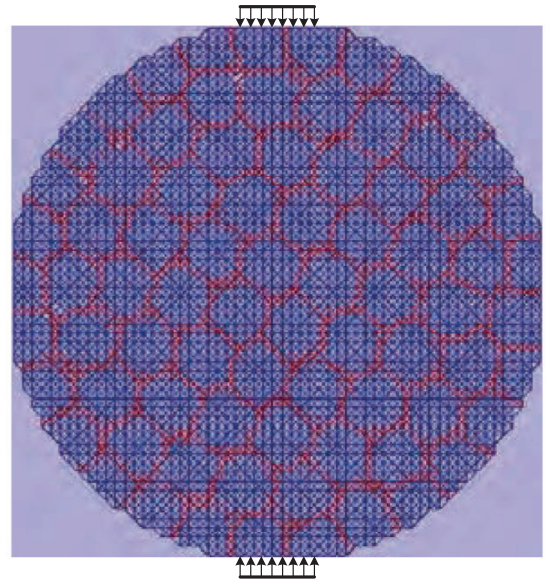

(a) Loading on this lattice model.

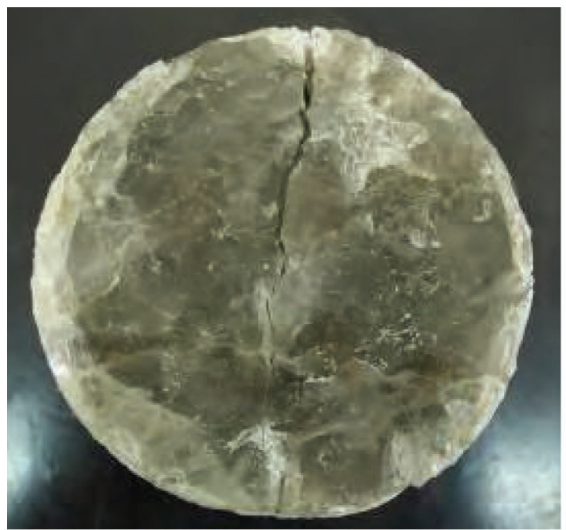

(c) Failure mode of lab test from Reference [50].

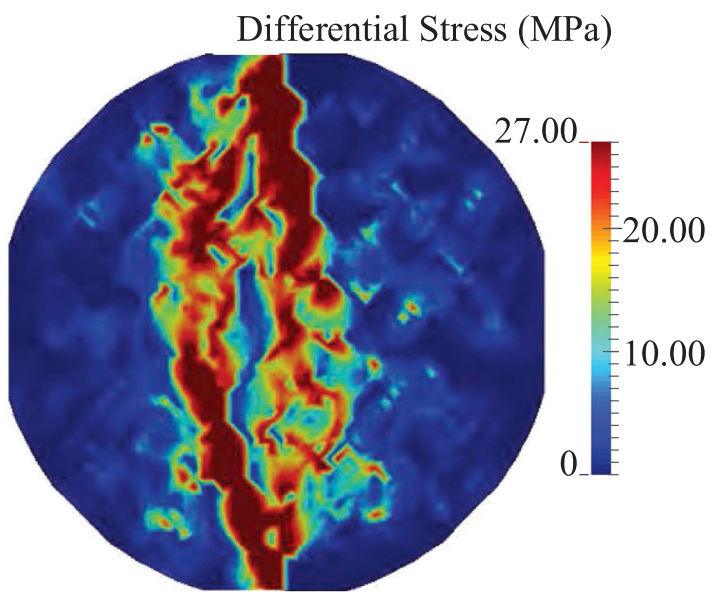

(b) Local differential stress.

Displacement Magnitude ( $\mathrm{mm})$

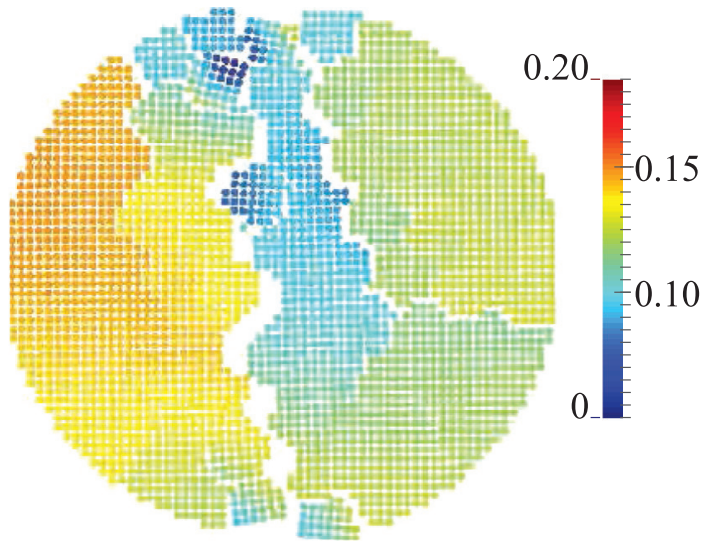

(d) Failure mode and displacement magnitude of lattice model.

Fig. 9. Lattice model of Brazilian tension test compared with lab measurement.

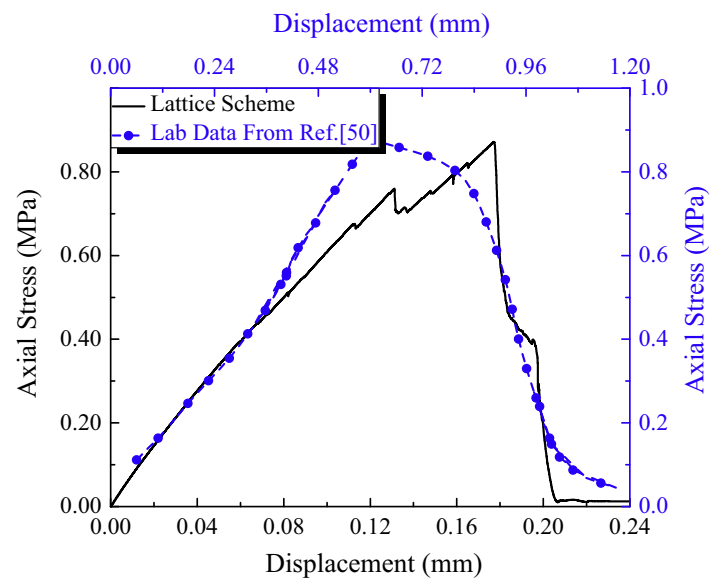

Fig. 10. The axial stress to vertical displacement of Brazilian test compared with lab measurement.

nearly linearly with regard to strain rate, respectively; whereas, the uniaxial compressive strength, the Brazilian tensile strength and their ratio generally revealed a general trend of rise with a trifling fluctuation. When strain rate is slower than $5.0 \mu \mathrm{m} / \mathrm{s}$, all the

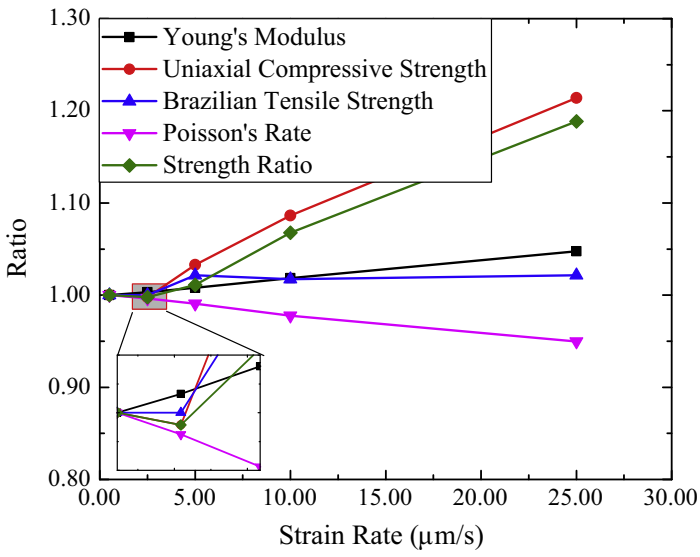

Fig. 11. Strain rate effect on the mechanical properties with a given non-viscous damping.

relative errors are within $3 \%$. Therefore, strain rate of $5.0 \mu \mathrm{m} / \mathrm{s}$ may be treated as a balance between accuracy and efficiency.

Input parameters, i.e. cohesive force, dilation/friction angle and the tensile strength for both lattice matrix and grain boundaries, 


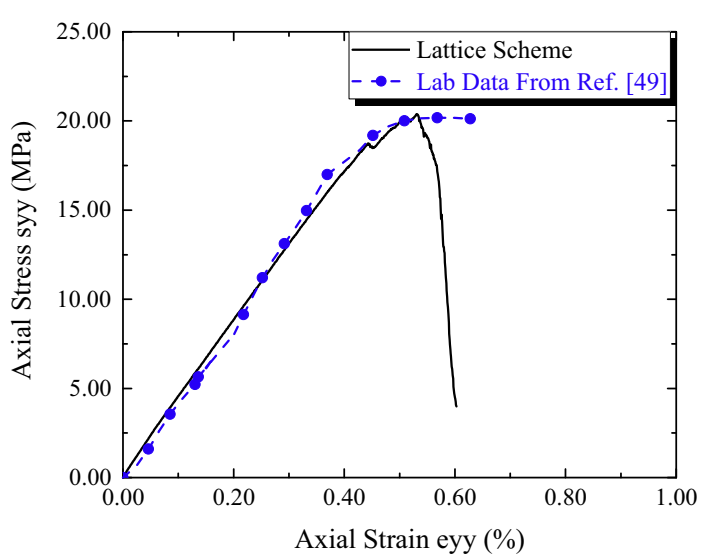

Fig. 12. Stress-strain curve obtained from uni-axial compression test simulations compared with lab data.

mutually decide the macroscopic compressive strength [54]. Hence, the objective function can be concluded as

$R_{3}\left(\mathbf{x}_{3}\right)=\sum_{i=1}^{N}\left(\frac{(\sigma)_{i}\left(\mathbf{x}_{3}\right)-\sigma_{0}}{\sigma_{0}}\right)^{2}$

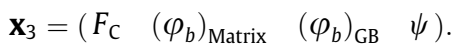

Due to brittle or quasi-brittle failure mode in most of unconfined compression tests of rock salt, the experimental data after reaching the stress peak, tending to be too ductile is filtered out. Fig. 12 shows the comparison results with all optimal values. At the beginning, the stress-strain relationship behaves in a linear and elastic way. The plastic deformation starts with increasing axial strain $e_{y y}$. When the value of $e_{y y}$ exceeds $0.52 \%$, the curve drops sharply with the compressive strength of $21.22 \mathrm{MPa}$.

Fig. 13 shows the local differential stress distributions of the specimen at different axial strain levels. It reveals that most of the cracks nucleate at the grain boundaries and largely parallel to the direction of the axial compression. Longitudinal splitting predominates in the failure mode of this sample. The reasons causing the phenomenon combined with low confinement tests is explained later. Response curves and deformation/failure modes are nearly in accord with experimental evidences [49]. As a summary, input parameters used in the simulations are listed in Table 2.

\subsection{Confinement dependence}

When rock salt is buried under the ground, serving as resources, nuclear waste or industrial waste repository, its confining pressure increases with the burial depth. Usually, deterioration mechanism can be changed by that varied confinement level. Failure modes may transit from brittle faulting to plastic flow with rising pressure [55], which is an important behaviour in many geologic situations, such as the tectonics of faulting or deformation band formation, or even some engineering contexts $[55,56]$. Hence, it is necessary to study the dependence of rock salt under various confinement levels. The biaxial compression tests are carried out on the same sample to use confining pressures between 0.2 and $20 \mathrm{MPa}$. In order to achieve desired response curves, the maximum moving velocity of lateral displacement boundary conditions controlling the confinements is adjusted separately during the biaxial compression process.

\subsubsection{Effect on compressive strength}

As observed in Fig. 14, a non-linear failure envelop is obtained by reasonable adjustments of initial and boundary conditions even based on a linear Mohr-Coulomb criterion [28]. The confinement of $10 \mathrm{MPa}$ was referred to as the onset of the brittle-ductile transition as mentioned in Ref. [49]. Wong and Baud ever discussed this trendency [55] and argued it might imply a transition to cataclastic flow or crystal plasticity. They attributed the cataclastic flow to two factors: friction and porosity changes caused by rearrangement of the fragments [55]. While, the crystal plasticity was used to describe slip and twinning within grains. To further investigate the mechanical deterioration changes during that process, four typical biaxial tests with confinement of $0.2 \mathrm{MPa}, 5 \mathrm{MPa}$, $10 \mathrm{MPa}$ and $20 \mathrm{MPa}$ are analyzed in more details.

Fig. 15 indicates the deviatoric stress $q$ varies with the axial strain $e_{y y}$. Elastic behaviour dominates $q-e_{y y}$ curves in a small deformation process. After axial stress $\sigma_{y y}$ achieves the strength criterion, the plastic deformation starts. Some interactions fall in tension or shear and new frictional contacts are created. This inelastic phase is no longer reversible. Rising confinement levels tend to improve the compressive strength, from about $21.22 \mathrm{MPa}$ of the unconfined compression test to $23.32 \mathrm{MPa}, 48.02 \mathrm{MPa}$ and 61.47 MPa for $0.2 \mathrm{MPa}, 5 \mathrm{MPa}$ and $10 \mathrm{MPa}$ confining pressure, respectively. At confinement of $10 \mathrm{MPa}$, the deviatoric stress is stabilized roughly with axial strain. Presumably, that's because the induced stress due to compressive strain and new created interac-

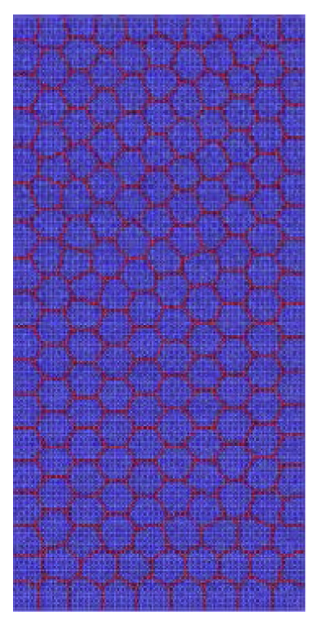

(a) Original specimen.

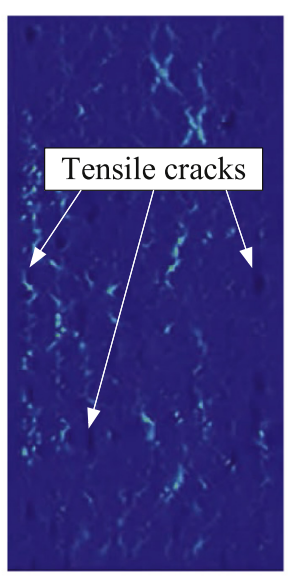

(b) At $e_{y y}=0.10 \%$.

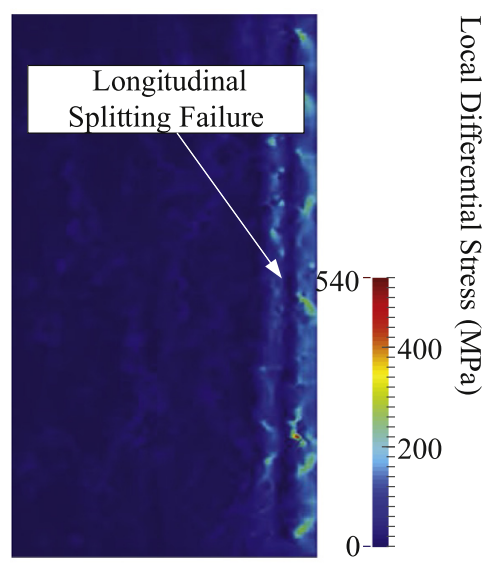

(c) At $e_{y y}=0.53 \%$.

Fig. 13. Cracking along the grain boundaries under uniaxial compression process. 
Table 2

Input parameters.

\begin{tabular}{lll}
\hline Material parameters & Lattice matrix & Grain boundary \\
\hline Friction Angle $\varphi_{\mathrm{b}}\left(^{\circ}\right)$ & 20 & 18 \\
Dilation Angle $\psi\left({ }^{\circ}\right)$ & 0 & 10 \\
Maximum Tensile Force $F_{\mathrm{n}, \max }(\mathrm{N})$ & $\backslash$ & 0.12 \\
Cohesive Force $F_{\mathrm{c}}(\mathrm{N})$ & 1.44 & 1.44 \\
Residual Friction Angle $\varphi_{\mathrm{c}}\left(^{\circ}\right)$ & 20 & 18 \\
Soft Parameter $k_{\mathrm{sf}}(-)$ & $\backslash$ & 0.05 \\
\hline
\end{tabular}

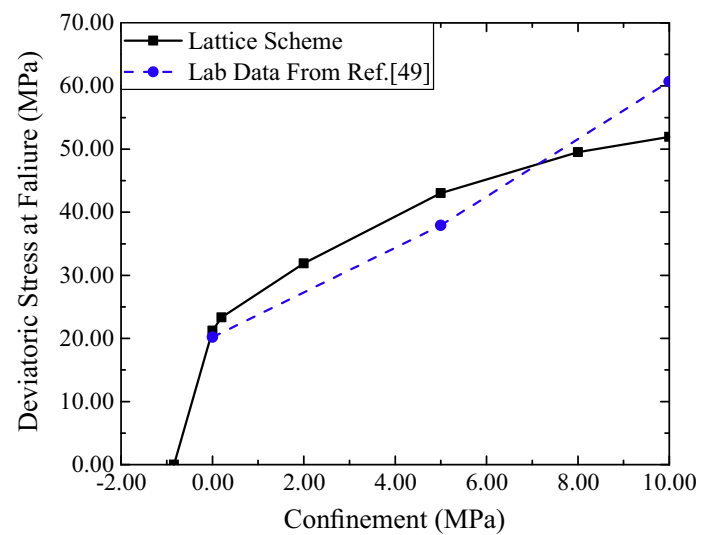

Fig. 14. Failure envelope of biaxial compression tests compared with lab measurement.

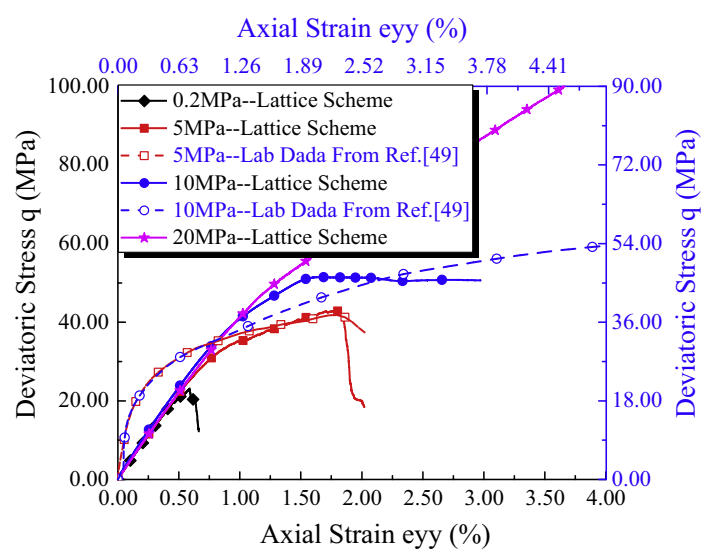

Fig. 15. Deviatoric stress with respect to the axial strain.

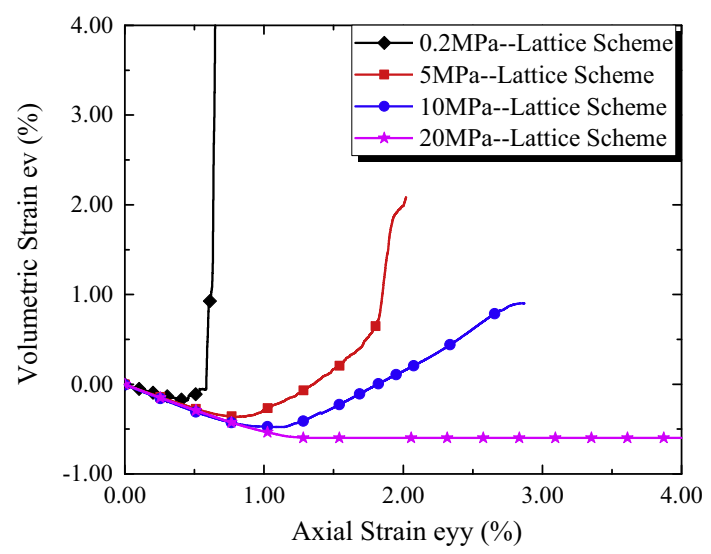

Fig. 16. Volumetric strain with respect to the axial strain. tions just make up the stress relief caused by broken springs. When the confinement exceeds $20 \mathrm{MPa}$, the strain generally hardens after the samples deform up to yield, contrary to the strain softening at lower pressures.

\subsubsection{Effect on volume changes}

The volume change $e_{\mathrm{V}}-e_{y y}$ results are illustrated in Fig. 16. Two opposing effects make contributions to the changes in the deformation. At the elastic phase, volume decreases in an approximately linear way. The axial compressive strain values are larger than the their transverse expansion, and their coefficient is $1 / v$ due to Poisson effect. At the plastic phase, springs breakage causes the collapse of lattice cells, continuing to reduce the volumetric strain. With increasing deviatoric stress, micro-cracking and sliding between grain boundaries occurs, which leads to dilate in volume. At low pressures of $0.2 \mathrm{MPa}$ and $5 \mathrm{MPa}$, volume increases dramatically at about 0.67 and 2.00 per cent axial strain when failure occurs. There appears a near infinite slope after reaching the minimum of $e_{\mathrm{V}}$ where the compressive strain is so small relatively that can be neglected. On the contrary, the changes at high pressures of $10 \mathrm{MPa}$ and $20 \mathrm{MPa}$ are about $0.02 \%$ and $-0.60 \%$ at the axial strain of $2.00 \%$, respectively. Accordingly, it may be predicted that the confinements incline to postpone the extremum and then decline in slope value. At the confinement of $20 \mathrm{MPa}$, it's noteworthy the axial strain happens to compensate for the transverse deformation, volumetric strain approximately a constant value, after the specimen yield.

These tendencies of deviatoric stress versus the axial strain and volumetric strain to axial strain curves are comparable with experimental results $[49,21]$. Currently, similar $q-e_{y y}$ curves have ever been attained by other numerical methods in limited studies of salt rock, but $e_{\mathrm{V}}$ in those simulations can't fully correspond to laboratory tests, which has been commented by Müller et al. [30]. Mostly, those approaches didn't involve neither the micro-crack openings within crystal grains nor updated frictional contacts that actually exist and may cause the volume changes as well. While, in this scheme, these axial strain values are a little bit smaller than the experimental data. That's because the deformation process may have already involved the time-dependent impact [30], such as creep deformation, in laboratory, even for relatively short term experiments with the strain rate order of $10^{-5} / \mathrm{s}[49,21]$. Besides, a different specimen configure, e.g., size, shape [55] and ratio of height to width, may contribute to those differences as well.

\subsubsection{Effect on fabric tensors}

In the above sections, the compressive strength, axial shortening, volumetric strain, etc., have been analyzed. While, not only do these scalar quantities involve in confinement tests, but also vector and tensor quantities [57]. Pre-existing discontinuities and stress-induced micro-cracking and micro-crack growth in preferential directions [58] may render the solid anisotropic. Usually, this anisotropy or fabric is effectively characterized by the use of distributions of directional data, termed as fabric tensors [57,59]. It can be computed by

$F_{i j}=\frac{1}{N} \sum n_{i} n_{j}$

which may help us to perceive the interplays.

To get the dependence of fabric tensors on confinements, we record every nodal force and gather statistics of the directional distributions. Rose diagrams within the $X Y$-plane of force normals for mass nodes at the compression peaks are illustrated in Fig. 17. The lateral orientation, $X$ axis, is set as the $0^{\circ}$ reference. At the confinement of $0.2 \mathrm{MPa}$ (Fig. 17(a)), forces' orientations prefer the directions of $0^{\circ} / 180^{\circ}$. For the $5 \mathrm{MPa}$ test (Fig. 17(b)), angles in range from $0^{\circ}$ to $90^{\circ}$ and $180^{\circ}$ to $270^{\circ}$ occupy larger proportions, whereas 


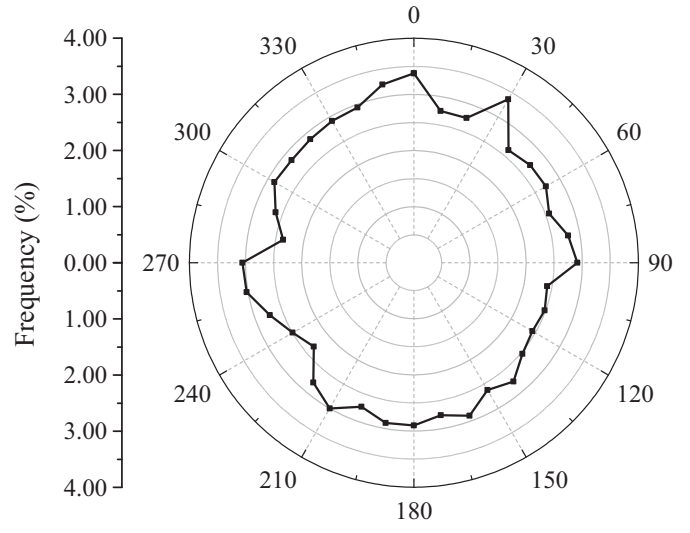

(a) At confinement of $0.2 \mathrm{MPa}$.

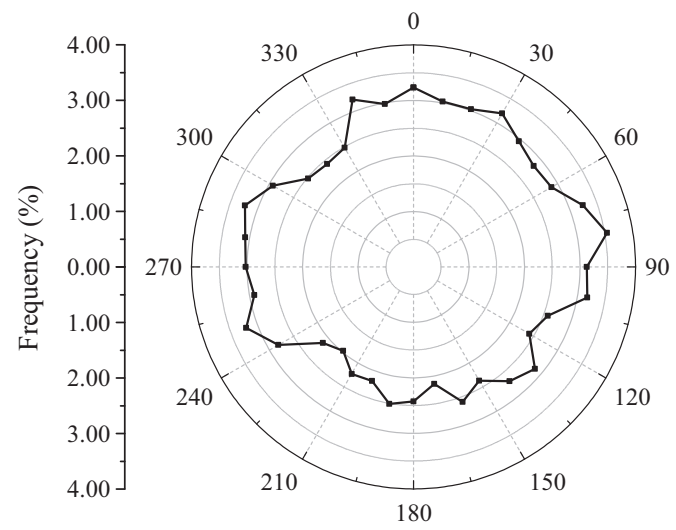

(c) At confinement of $10 \mathrm{MPa}$.

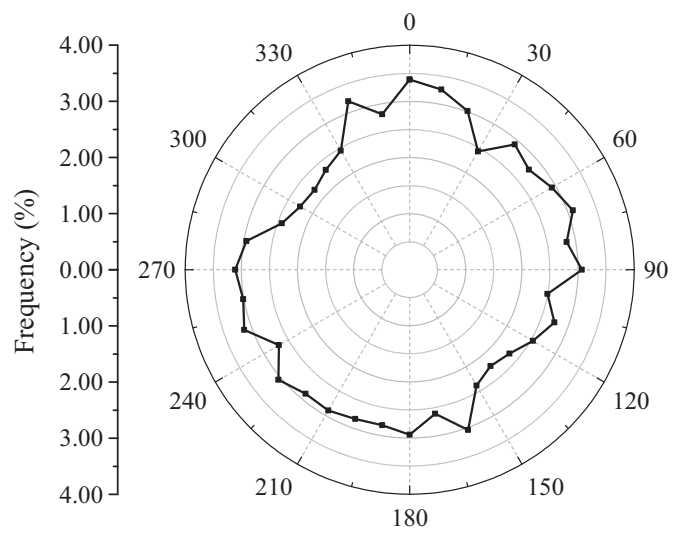

(b) At confinement of $5 \mathrm{MPa}$.

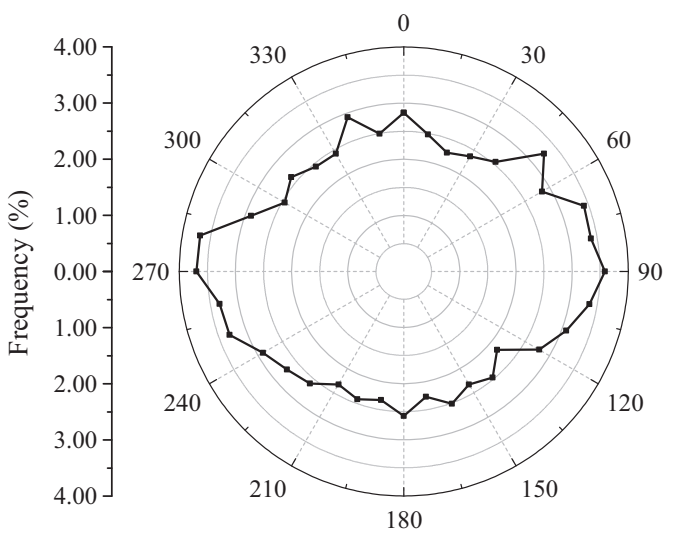

(d) At confinement of $20 \mathrm{MPa}$.

Fig. 17. Normal distributions at the compressive strength at different confinements.

their fabrics at confining pressure of $10 \mathrm{MPa}$ (Fig. 17(c)) and $20 \mathrm{MPa}$ (Fig. 17(d)) almost align with the deviatoric compression axis. These changes hint at different failure patterns.

\subsubsection{Effect on failure modes}

How do failure modes change at different confinement levels? What kind of cracks cause failure, tensile or shear? Does crack type switch with the transition from brittle to ductile? So far, these questions still remain significant and hot topics in the field of halite studies and applications. This section, we focus on those points, combine the lattice simulation with previous opinions and try to provide a more comprehensive and reasonable remark.

Fig. 18 depicts the different failure modes with increasing confinements. Agree with available literatures [30,21], under low confinement, here $0.2 \mathrm{MPa}$ (Fig. 18(a)), the failure mode is similar to the uniaxial compression test, where the splitting failure is dominant. As far as 1965, in the views of lab experiments, Gramberg gave tentative explanation [60]. He argued that this fracture mode was only observed in brittle materials due to tension and called it tensile brittle fracture, also cleavage fracture [60]. Subsequently, he and other researchers [61-64] tried to obtain more general conclusions. Broadly, tensile cracking is believed to be the essential factor. While, does this process come along with shear failure and how much percentage do the shear cracks take. Up until now, the investigation of the answers to those inquiries might still be going on and it is discussed in this paper later. When the confining pressure reaches $5 \mathrm{MPa}$, the sample is failed by the formation of a localized shear fracture (Fig. 18(b)). At the confinement of $10 \mathrm{MPa}$
(Fig. 18(c)) and $20 \mathrm{MPa}$ (Fig. 18(d)), no evident failure macroscopicly is found even when the axial strain is more than $3.0 \%$, relatively large compared with lower pressure tests.

Associated local differential stress distributions are illustrated in Fig. 19 with the same colour bar, which may help to better understand the failure modes variation. The macroscopic failure of specimen leads to stress relief. That explains why parts of local differential stress remains zero in Fig. 13(c), Fig. 19(a) and (b). The local differential stress at $e_{y y}=4.00 \%$ under the confinement of $20 \mathrm{MPa}$ nearly distribute uniformly (Fig. 19(d)). While, at the confinement of $10 \mathrm{MPa}$ (Fig. 19(c)), the transitional failure mode, parts of differential stress along the grain boundaries are zero, which means cracks also cleavage along the boundaries. That is further revealed by Fig. 20. In these figures, the crack distributions are shown and crack types are distinguished by different colours: red cracks mean causing by tension and yellow ones by shearing. Fig. 20(a) validates that crack development under low confinement is predominantly due to tension, which has been demonstrated before, but not the unique crack type. From our results, we can know shear cracks do stimulate brittle fracture as well. At the confinement of $5 \mathrm{MPa}$ (Fig. 20(b)), shear cracks nucleate along the diagonal line of this rectangle sample and form a localized shear band as a consequence of tensile and shear cracking. With the confining pressure of $10 \mathrm{MPa}$ and $20 \mathrm{MPa}$, cracks exist along inter- and intra-crystalline grains. However, it's hard to tell the differences between Fig. 20(c) and (d).

Therefore, the tensile and shear crack number ratios at different confinements are plotted in Fig. 21. Here, we choose the total crack 


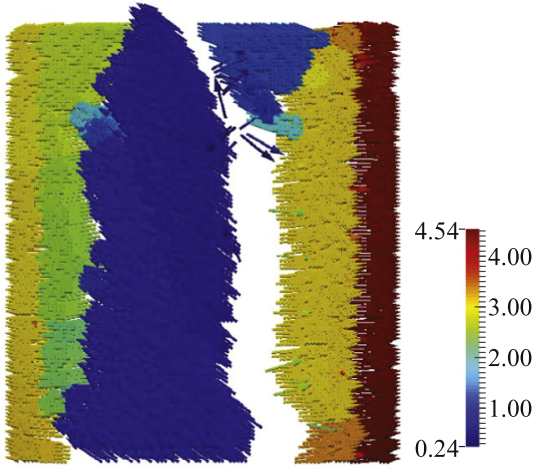

(a) $e_{y y}=0.67 \%$ at confinement of 0.2 $\mathrm{MPa}$.
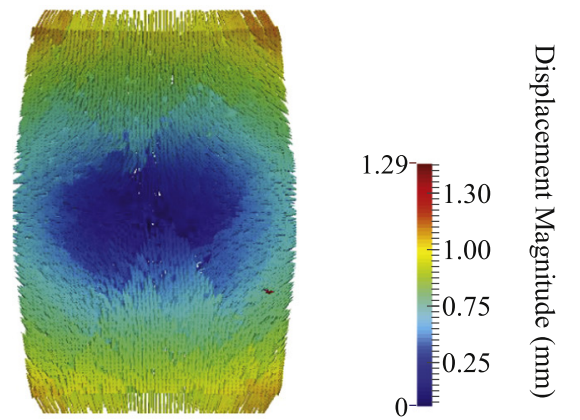

(c) $e_{y y}=3.00 \%$ at confinement of 10 $\mathrm{MPa}$.

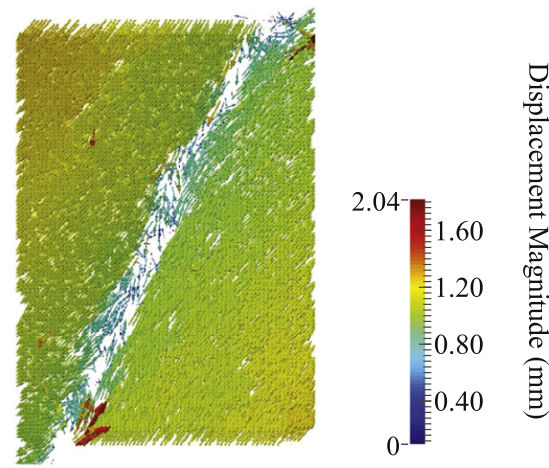

(b) $e_{y y}=2.00 \%$ at confinement of $5 \mathrm{MPa}$.
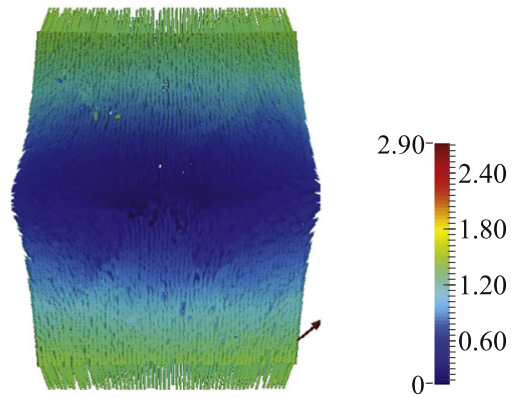

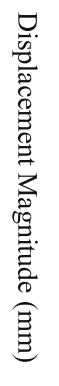

(d) $e_{y y}=4.00 \%$ at confinement of 20 $\mathrm{MPa}$.

Fig. 18. Displacement distributions after reaching the compressive strength at different confinements.

number at $e_{y y}=0.67 \%$ under confinement of $0.2 \mathrm{MPa}$ as the reference value. The ratios of crack number to basis value are represented by vertical axis. In Fig. 21(a), at the beginning, nearly no cracks occur. Then, at $e_{y y}=0.10 \%$, tensile cracks increase first and shear cracks develop at $e_{y y}=0.40 \%$ later. There is a sharp boom of both tensile and shear cracks at the axial strain about $0.60 \%$. After failure, the tensile cracks number is four times as much as shear ones. At the confinement of 5 MPa (Fig. 21(b)), tensile cracks form earlier than the shear ones as well. After the axial strain reaches about $1.0 \%$, shear cracks number is on the sharp rise, whereas the tensile cracks stay the same level. When the sample fractures, there is an abrupt growth of two kinds of cracks (Fig. 21(b)) as that at confining pressure of $0.2 \mathrm{MPa}$ (Fig. 21(a)). In contrary, for the crack variations at the confinements of $10 \mathrm{MPa}$ and $20 \mathrm{MPa}$, the cracks number keep stable at axial strain more than 3.0\%. At the confinement of $20 \mathrm{MPa}$, during the isotropic compression stage, the sample has already accumulated almost $10 \%$ of tensile cracks (Fig. 21(d)), which notably differs from that at confining pressure of $0.2 \mathrm{MPa}, 5 \mathrm{MPa}$ or $10 \mathrm{MPa}$. Generally, it may be concluded that the increasing confinement levels reduce limitedly the development of tensile cracks from $80 \%$ to about $50 \%$, whereas increase the shear cracking largely. In addition, higher confinements help to stabilize the propagation and proliferation of both tensile and shear micro-cracking.

Essentially, based on this research, it may be maintained that the crack type and proportion caused by external conditions gives rise to the distinctions of mechanical deterioration among different confining pressure tests. With the increase of confinement, failure modes transit from plastic brittle to plastic ductile. In the earlier work, this plasticity improvement was treated as one consequence of suppression of micro-cracks opening and propagation along gain boundaries. Howbeit these simulation results manifest that the tension influence is quite limited according to the foregoing discussion. It may be more likely to be attributed to the breakage and creation of contacts. High stress causes massive mirco-cracks and the sample tends to be cataclastic. Fractures prefer to appear along gain boundaries and then the resultant forces acting on the every whole grain lead to movements around other gains. Within crystalline grains, residual forces and moments make these mass nodes slip or may climb and then generate new fictional contacts with updated neighbouring nodes within the given range. This process accounts for the rearrangements of gains, lattice dislocation and improvement of crystal plasticity. Therefore, this transition can be a complex consequence of the interplays of multiple deformation mechanisms, including the changes in slip characters [65], the frictional strengthening [28] and crystal plasticity.

\subsection{Evaluation of predictive capability}

A consistent simulation procedure for this grain-based lattice is described in Sections 3.1 and 3.2. In this section, the capability of the model in predicting mechanical behaviour of rock salt will be discussed. The objective of our work is to provide a feasible model to study quantitatively the interplays of rock salt, and make sure the key points in mechanical deterioration could be captured. For this purpose, we mainly focus on the comparison of general tendency of stress-strain and volumetric strain to axial strain curves, strain value at stress peak in calibration tests, stress strength and macroscopic failure modes with available experimental data. 

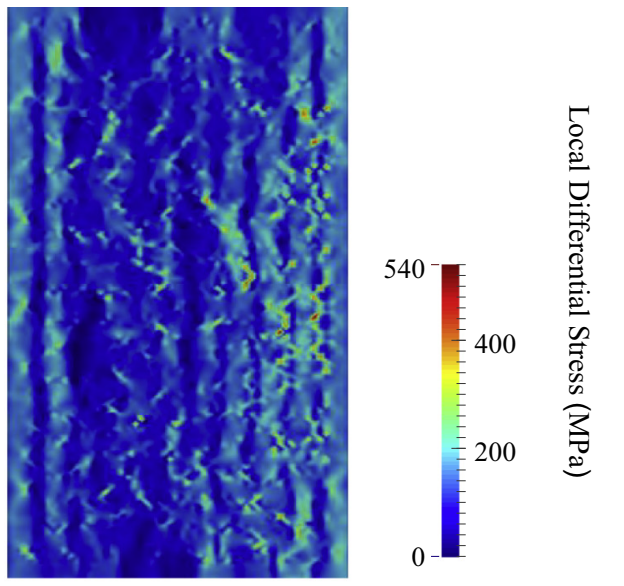

(a) $e_{y y}=0.67 \%$ at confinement of 0.2 $\mathrm{MPa}$.
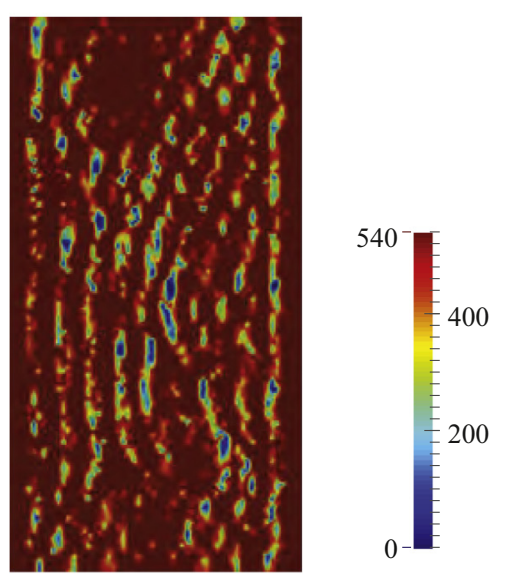

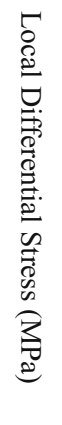

(c) $e_{y y}=3.00 \%$ at confinement of 10 $\mathrm{MPa}$.

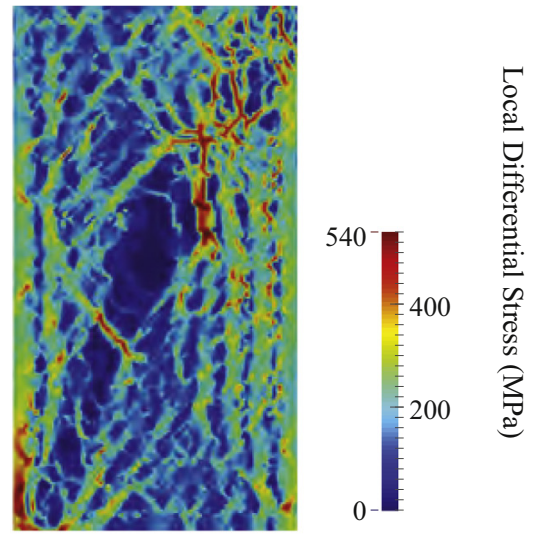

(b) $e_{y y}=2.00 \%$ at confinement of $5 \mathrm{MPa}$.

Fig. 19. Local differential stress distributions after reaching the compressive strength at different confinements.

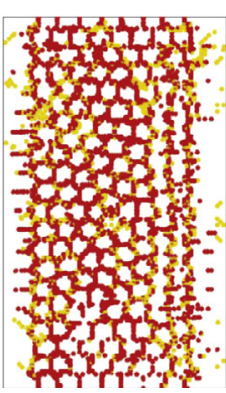

(a) $e_{y y}=0.67 \%$ at confinement of $0.2 \mathrm{MPa}$.

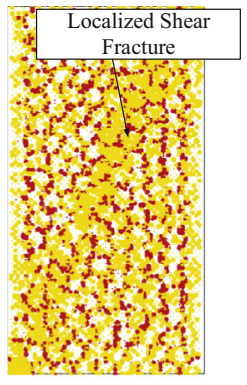

(b) $e_{y y}=2.00 \%$ at confinement of 5 MPa.

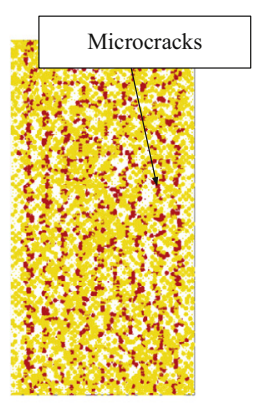

(c) $e_{y y}=3.00 \%$ at confinement of 10 MPa.

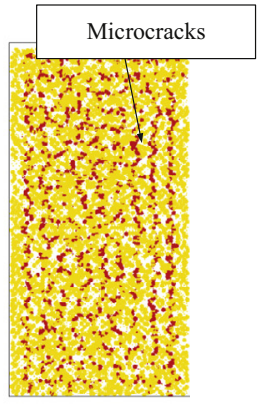

(d) $e_{y y}=4.00 \%$ at confinement of 20 MPa.

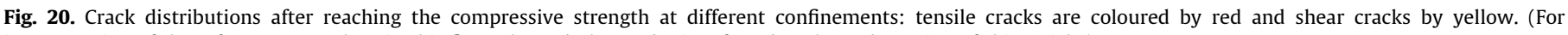
interpretation of the references to colour in this figure legend, the reader is referred to the web version of this article.)

\subsubsection{Elastic phase}

This phase is mostly controlled by the elastic material constants, like Young's modulus and Poisson ratio. In this lattice model, the Young's modulus is decided by the normal and shear stiffness. Additionally, Poisson ratio also is dependent on the value of given mirco-rotation inertia. Due to the simplicity of the opti- 


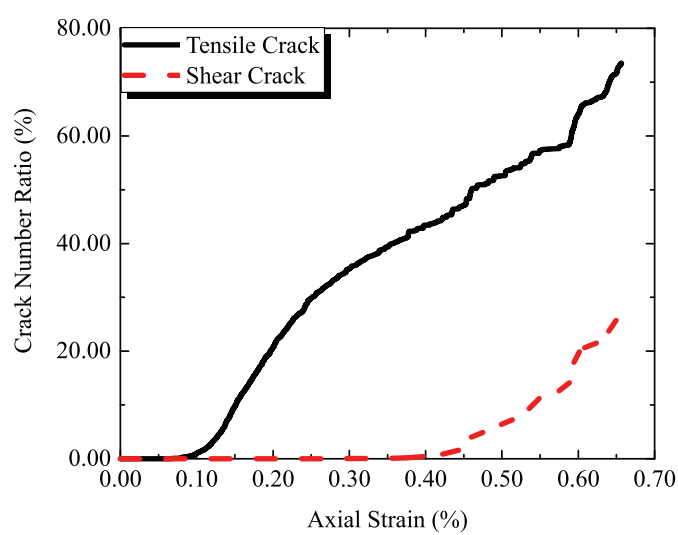

(a) $e_{y y}=0.67 \%$ at confinement of $0.2 \mathrm{MPa}$.

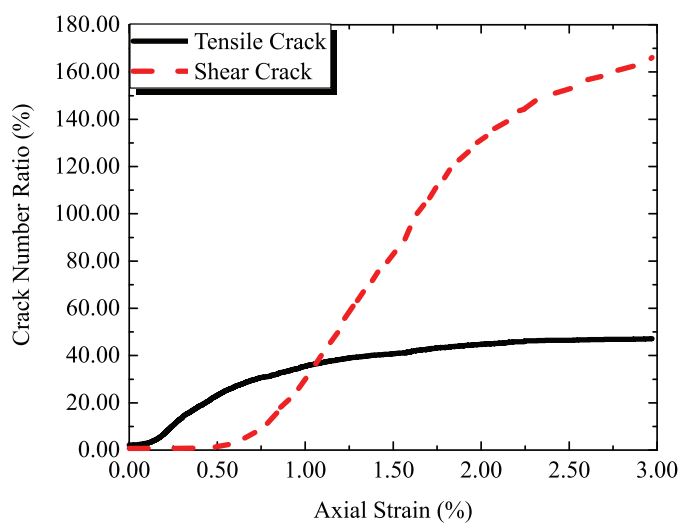

(c) $e_{y y}=3.00 \%$ at confinement of $10 \mathrm{MPa}$.

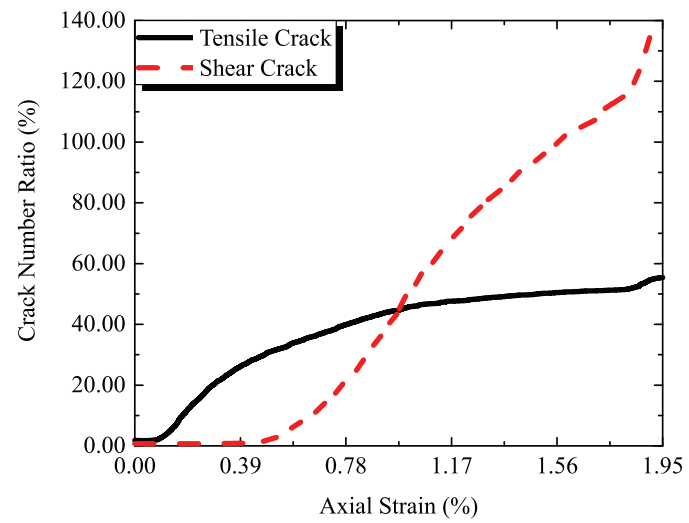

(b) $e_{y y}=2.00 \%$ at confinement of $5 \mathrm{MPa}$.

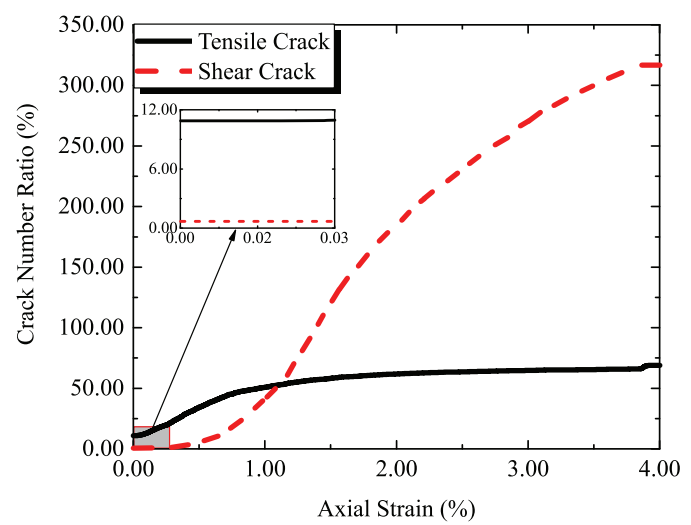

(d) $e_{y y}=4.00 \%$ at confinement of $20 \mathrm{MPa}$.

Fig. 21. Tensile and shear cracks number ratio variation with respect to axial strain at different confinement levels.

mization function expressed in Eq. (17), relatively reliable elastic parameters could be calculated by a few iterations. According to the results shown in the foregoing discussion, the curves in the elastic phase agree well with the laboratory comparison. It may be argued that this model has the exact ability to predict the mechanical behaviour of rock salt within elastic deformation.

\subsubsection{Inelastic phase}

Generally, our simulations results show that the general tendency of $q-\varepsilon_{y y}, \varepsilon_{\mathrm{V}}-\varepsilon_{y y}$ curves, stress strength, macroscopic failure modes and micro-crack distributions at meso-level are comparable with the experimental data. However, the axial strain at the stress peak or yield is slightly deviated from experimental reference. The reasons for the phenomena are various and directly related to the inelastic components in constitutive law and the failure/yield criterion controlling the breakage of the springs. In the perspective of this model, the material parameter identification may cause some artifacts as well.

The contact law used in our approach is lack of the inelastic term, like viscous damping and temperature-dependent effect [66]. Even if breakage-and-creation mechanism of interactions is introduced, it may be insufficient to compensate for accumulated strain generated in the long-term tests. Therefore, advanced interactions need to be further explored. Meanwhile, a Mohr Coulomb criterion [67] and tension cut-off function accounts for the shear and tension failure/yield behaviours in this paper. Taking more complex criteria, like nonlinear parabolic criterion [68], in consideration might be a good attempt. In the calibration stage, the optimization extent of material parameters depends on the objective function, experimental data and iterations. The function for solving the inverse problem is in a widely-used form [44,69,70]. Part of target data needs some reasonable adjustments to fit a statistical tendency, due to the differences existing in the experimental specimens. With increasing number of iterations on a higher performance computer, better values may be identified.

In summary, even though our model isn't perfect and still need polish, fortunately, the core issues in these simulation results could be comparable with the experimental counterparts. An alternative and promising approach presents the ability to simulate the halite at crystalline grain scale in more effective and time-saving way. Meanwhile, it may help to better understand and explore quantitatively the dependence of the mechanical deterioration of inter crystalline and intra crystal on confinement.

\section{Conclusions}

The determination of linear elasticity under low stress conditions, the compressive/residual strength under different confinements [71] and associated mechanical deterioration is considered as one of the crucial processes in the application of rock salt [30]. Increasing number of projects at great depths generate a large amount of challenges in the development of the underground infrastructures, such as salt cavern. Unfortunately, as for the interplays of failure mechanism inside of the crystal structure, the exploration remains insufficient and limited, despite conventional approaches, in-situ or laboratory measurements have provided us with several data. Thus, new techniques and means need to be developed. 
In this paper, a promising approach, a grain-based lattice scheme, is developed and the related simulation procedure is present consistently. The essential features of mechanical deterioration in halite confinement tests can be replicated. Then, to some degree, the brittle-ductile transition phenomenon was captured here. Unlike existing methods, experimental tests or theoretical analysis, the model shows the potential to study quantitatively and visually on both the inside factors and meso-mechanisms. Distinct from other numerical simulations, confining pressure effects on rock salt are analyzed from multi-perspectives in more efficient and simpler way. The primary conclusions and advantages of this study are summarized as follows.

1. This proposed scheme seems to be an alternative choice to investigate the rock salt at grain scale effectively. Crystal slips and fractures nucleate along the grain boundaries, and cracks also could occur within the interior of the crystal grains. Due to the introduction of this grain-based lattice scheme, the calculation efficiency is improved from several aspects: firstly, the nodes of sample and initial interactions generated in precomputed way; secondly, the contacts between every two non-spherical grains are in a point-to-point manner instead of other complex contacts, such as edge-to-edge, edge-to-corner and facet-to-corner; also, the approach uses an explicit time marching formulation, central difference scheme, and simplifies the integration of motion equations.

2. Preliminary studies show both non-viscous damping and strain rate affect the response curves and the latter poses greater impact on the results. Tensile strength is mainly decided by the tensile strength of the interfaces of crystal grains, and the macroscopic compressive strength is relevant to cohesion, tensile strength and dilation/friction angle for both grain boundaries and the lattice matrix.

3. Increasing confinements strengthen plastic characteristics of the specimen and then lead to a transition from stress softening to stress hardening. The stress peak is improved up to 61.47 MPa under the confinement of $10 \mathrm{MPa}$. It is nearly tripled compared with the uni-axial compression tests. The sample tends to be ductile beyond the confining pressure of $10 \mathrm{MPa}$, in contrast to the brittle deformation under lower confinements. Different from previous schemes, this model could achieve a comparable trend of volume-change with experimental tests. The differences of fabric tensors implicit the different confinement levels effect on failure patterns.

4. Align with experimental evidences, the failure modes of halite can be transited from cleavage fracture to ductile deformation by the aid of sufficiently high confining pressure. The distinctions of failure modes at different confining pressure are the results of different crack type and proportion. To a limited extent, the tensile cracks can be reduced by high confinements, whilst higher confinements stabilize the crack generation. The scheme can account for multiple deformation mechanisms of salt-rock in the transitional mode: slip characters, the frictional strengthening and crystal plasticity.

\section{Acknowledgments}

This work is financially supported by the National Natural Sciences Foundation (Grant Nos. 11232012 and 11372320). Thanks are also due to Prof. Steve Sun for valuable advices and to the editors and anonymous reviewers for editorial assistance and insightful comments.

\section{References}

[1] Stormont J. In situ gas permeability measurements to delineate damage in rock salt. Int J Rock Mech Min Sci 1997;34:1055-64.

[2] Yang C, Daemen J, Yin J-H. Experimental investigation of creep behavior of salt rock. Int J Rock Mech Min Sci 1999;36:233-42.

[3] Urai J, Spiers C. The effect of grain boundary water on deformation mechanisms and rheology of rocksalt during long-term deformation. In: Proc 6th Conf Mech Beh of Salt. p. 149-58.

[4] Thoms R, Gehle R. A brief history of salt cavern use. In: The 8th world salt symposium, vol. 2. [S. 1.]: Elsevier; p. 207-14.

[5] Bräuer V, Reh M, Schulz P, Schuster P, Sprado K. Endlagerung stark wärmeentwickelnder radioaktiver abfälle in tiefen geologischen formationen deutschlands-untersuchung und bewertung von regionen in nichtsalinaren formationen, Hannover, Bundesanstalt für Geowissenschaften und Rohstoffe; 1994.

[6] Helton JC, Martell M-A, Tierney MS. Characterization of subjective uncertainty in the 1996 performance assessment for the waste isolation pilot plant. Rel Eng Syst Safety 2000;69:191-204.

[7] Gevantman LH, Lorenz J, Haas Jr J, Clynne M, Potter R. Physical properties data for rock salt. Technical Report, National Bureau of Standards, Washington, DC USA; 1981.

[8] Senseny P, Hansen F, Russell J, Carter N, Handin J. Mechanical behaviour of rock salt: phenomenology and micromechanisms. In: International journal of rock mechanics and mining sciences \& geomechanics abstracts, vol. 29. Elsevier, pp. 363-78.

[9] Hunsche U, Hampel A. Rock salt-the mechanical properties of the host rock material for a radioactive waste repository. Eng Geol 1999;52:271-91.

[10] Sriapai T, Walsri C, Fuenkajorn K. True-triaxial compressive strength of maha sarakham salt. Int J Rock Mech Min Sci 2013;61:256-65.

[11] Hunsche $U$, Albrecht $H$. Results of true triaxial strength tests on rock salt. Eng Fract Mech 1990;35:867-77.

[12] Munson DE. Preliminary deformation-mechanism map for salt (with application to WIPP). Technical Report, Sandia Labs., Albuquerque, NM (USA); 1979.

[13] Hunsche U. Uniaxial and triaxial creep and failure tests on rock: experimental technique and interpretation. In: Visco-plastic behaviour of geomaterials. Springer; 1994. p. 1-53.

[14] Charpentier J. Creep of rock salt at elevated temperature. In: Proceedings of second conference on mechanical behaviour of salt. Clausthal-Zellerfeld, Germany: Trans Tech Pub; p. 131-6.

[15] Salzer K, Günther R, Minkley W, Popp T, Wiedemann M, Hampel A, et al. Joint projects on the comparison of constitutive models for the mechanical behavior of rock salt i. Overview of the projects, reference mine for 3-d benchmark calculations, in-situ measurements and laboratory tests. Mech Behav Salt VII 2012:221.

[16] Hampel A, Salzer K, Günther R, Minkley W, Pudewills A, Leuger B, et al. Joint projects on the comparison of constitutive models for the mechanical behavior of rock salt-ii. Overview of the models and results of 3-d benchmark calculations. In: Proceedings of the 7th conference on mechanical behavior of salt, Paris; 16-19 April 2012. p. 231-40.

[17] Günther R, Salzer K. Advanced strainhardening approach: a powerful creep model for rock salt with dilatancy, strength and healing. In: Proceedings of the 7th conference on mechanical behavior of salt, Paris; 16-19 April 2012. p. 1322.

[18] Haupt M. A constitutive law for rock salt based on creep and relaxation tests. Rock Mech. Rock Eng 1991;24:179-206.

[19] Cristescu N. A general constitutive equation for transient and stationary creep of rock salt. In: International journal of rock mechanics and mining sciences \& geomechanics abstracts, vol. 30. Elsevier. p. 125-40.

[20] Ma H, Yang C, Li Y, Shi X, Liu J, Wang T. Stability evaluation of the underground gas storage in rock salts based on new partitions of the surrounding rock. Environ Earth Sci 2015;73:6911-25.

[21] Düsterloh U HK et al. Joint project iii on the comparison of constitutive models for the mechanical behavior of rock salt ii. Extensive laboratory test program with clean salt from wipp. Mech Behav Salt VIII 2015:13-21.

[22] Evans DG, Nunn JA. Free thermohaline convection in sediments surrounding a salt column. J Geophys Res: Solid Earth 1989;94:12413-22.

[23] Gil J, Jurado M. Geological interpretation and numerical modelling of salt movement in the barbastro-balaguer anticline, southern pyrenees. Tectonophysics 1998;293:141-55.

[24] Thoms RL, Char CV, Bergeron WJ, et al. Finite element analysis of rock-salt pillar models. In: The 14th US Symposium on Rock Mechanics (USRMS). American Rock Mechanics Association.

[25] Moghadam SN, Mirzabozorg H, Noorzad A. Modeling time-dependent behavior of gas caverns in rock salt considering creep, dilatancy and failure. Tunn Undergr Space Technol 2013;33:171-85.

[26] Zhao G. Development of micro-macro continuum-discontinuum coupled numerical method 2010.

[27] Cundall PA. A computer model for simulating progressive large scale movements in blocky rock systems. In: Proc Symp Rock Fracture (ISRM), Nancy, vol. 1.

[28] Scholtès L, Donzé F-V. A DEM model for soft and hard rocks: role of grain interlocking on strength. J Mech Phys Solids 2013;61:352-69. 
[29] Bahrani N, Potyondy D, Pierce M. Simulation of brazilian test using PFC2D grain-based model. In: Proceedings of 21st Canadian rock mechanics symposium, Edmonton.

[30] Müller C, Lerch C, Otparlik K, Konietzky H. Simulation of the mechanical deterioration of rock salt at grain scale. Mech Behav Salt VII 2012:107.

[31] Ostoja-Starzewski M. Lattice models in micromechanics. Appl Mech Rev 2002;55:35-60.

[32] Hrennikoff A. Solution of problems of elasticity by the framework method. J Appl Mech 1941;8:169-75.

[33] Pazdniakou A, Adler P. Lattice spring models. Transp Porous Media 2012;93:243-62.

[34] Picallo CB, Lpez JM, Zapperi S, Alava MJ. From brittle to ductile fracture in disordered materials. Phys Rev Lett 2010;105:2982-8.

[35] Arslan A, Koehn D, Passchier CW, Sachau T. The transition from single layer to foliation boudinage: a dynamic modelling approach. J Struct Geol 2012:42:118-26.

[36] Talischi C, Paulino GH, Pereira A, Menezes IF. Polymesher: a general-purpose mesh generator for polygonal elements written in matlab. Struct Multidiscip Optim 2012;45:309-28.

[37] Damjanac B, Detournay C, Cundall PA. Application of particle and lattice codes to simulation of hydraulic fracturing. Comput Particle Mech 2015:1-13.

[38] Matsushima T, Katagiri J, Uesugi K, Tsuchiyama A, Nakano T. 3D shape characterization and image-based DEM simulation of the lunar soil simulant FJS-1. J Aerospace Eng 2009;22:15-23.

[39] Hagenmuller P, Chambon G, Naaim M. Microstructure-based modeling of snow mechanics: a discrete element approach. Cryosphere 2015:9:1969-82.

[40] Ivars DM, Pierce ME, Darcel C, Reyes-Montes J, Potyondy DO, Young RP, et al. The synthetic rock mass approach for jointed rock mass modelling. Int J Rock Mech Min Sci 2011;48:219-44.

[41] Potyondy D. A grain-based model for rock: approaching the true microstructure. Proceedings of Bergmekanikk i Norden 2010:225-34.

[42] Scholtès L, Donzé F-V, Khanal M. Scale effects on strength of geomaterials, case study: coal. J Mech Phys Solids 2011;59:1131-46.

[43] Harthong B, Scholtès L, Donzé F-V. Strength characterization of rock masses, using a coupled DEM-DFN model. Geophys J Int 2012;191:467-80.

[44] Eldred MS, Vigil DM, Dalbey KR, Bohnhoff WJ, Adams BM, Swiler LP, et al. Dakota, a multilevel parallel object-oriented framework for design optimization, parameter estimation, uncertainty quantification, and sensitivity analysis. In: Version 31 Users Manual Sand, Sandia National Laboratories, Po Box.

[45] Šmilauer V. Cohesive particle model using the discrete element method on the yade platform, Ph.D. thesis, Université de Grenoble; Czech Technical University in Prague; 2010. <http://www.cvut.cz>.

[46] Zhao S-F, Zhao G-F. Implementation of a high order lattice spring model for elasticity. Int J Solids Struct 2012;49:2568-81.

[47] Kozicki J, Donzé F. Yade-open dem: an open-source software using a discrete element method to simulate granular material. Eng Comput 2009;26:786-805.

[48] Zhao GF, Fang J, Zhao J. A 3d distinct lattice spring model for elasticity and dynamic failure. Int J Numer Anal Meth Geomech 2011;35:859-85.

[49] Liang W-g, Yang C-h, Zhao Y-s, Dusseault M, Liu J. Experimental investigation of mechanical properties of bedded salt rock. Int J Rock Mech Min Sci 2007; 44:400-11.

[50] Liu J, Pei J, Ma K, Zhou H, Hou Z. Damage evolution and fractal property of salt rock in tensile failure. In: Proceedings of the international symposium on underground storage of $\mathrm{CO}$, vol .2. p. 105-12.
[51] Fuenkajorn K, Phueakphum D. Effects of cyclic loading on mechanical properties of maha sarakham salt. Eng Geol 2010;112:43-52.

[52] Silberschmidt V, Silberschmidt V. Analysis of cracking in rock salt. Rock Mech Rock Eng 2000;33:53-70.

[53] Brady BH, Brown ET. Rock mechanics: for underground mining. Springer Science \& Business Media; 2013

[54] Bahrani N, Valley B, Kaiser P, Pierce M, et al. Evaluation of pfc2d grain-based model for simulation of confinement-dependent rock strength degradation and failure processes. In: 45th US Rock Mechanics/Geomechanics Symposium, American Rock Mechanics Association.

[55] Wong T-f, Baud P. The brittle-ductile transition in porous rock: a review. J Struct Geol 2012;44:25-53.

[56] Zheng Z, Sun WC, Fish J. Micropolar effect on the cataclastic flow and brittleductile transition in highporosity rocks. J Geophys Res Solid Earth 2016.

[57] Ken-Ichi K. Distribution of directional data and fabric tensors. Int J Eng Sci 1984:22:149-64.

[58] Wong T-f. Geometric probability approach to the characterization and analysis of microcracking in rocks. Mech Mater 1985;4:261-76.

[59] Wang K, Sun WC. Anisotropy of a tensorial bishop's coefficient for wetted granular matters. J Eng Mech 2015.

[60] Gramberg J. The axial cleavage fracture 1 axial cleavage fracturing, a significant process in mining and geology. Eng Geol 1965;1:31-72.

[61] Fairhurst C, Cook N. The phenomenon of rock splitting parallel to the direction of maximum compression in the neighborhood of a surface. In: Proceedings of the first congress on the international society of rock mechanics, vol .1. p. 68792.

[62] Holzhausen G, Johnson A. Analyses of longitudinal splitting of uniaxially compressed rock cylinders. In: International journal of rock mechanics and mining sciences \& geomechanics abstracts, vol. 16. Elsevier. p. 163-77.

[63] Horii H, Nemat-Nasser S. Compression-induced microcrack growth in brittle solids: axial splitting and shear failure. J Geophys Res 1985;90:3.

[64] Bhattacharya K, Ortiz M, Ravichandran G. Energy-based model of compressive splitting in heterogeneous brittle solids. J Mech Phys Solids 1998:46:2171-81.

[65] Johnston T, Davies R, Stoloff N. Slip character and the ductile to brittle transition of single-phase solids. Phil Mag 1965;12:305-17.

[66] Thomas HR, Sedighi M, Vardon PJ. Diffusive reactive transport of multicomponent chemicals under coupled thermal, hydraulic, chemical and mechanical conditions. Geotech Geol Eng 2012;30:841-57.

[67] Yao C, Jiang QH, Shao JF. Numerical simulation of damage and failure in brittle rocks using a modified rigid block spring method. Comput Geotech 2015;64:48-60.

[68] Yao C, Jiang QH, Shao JF, Zhou CB. A discrete approach for modeling damage and failure in anisotropic cohesive brittle materials. Eng Fract Mech 2016:155:102-18.

[69] Liu Y, Sun WC, Fish J. Determining material parameters for critical state plasticity models based on multilevel extended digital database. J Appl Mech $2016 ; 83$.

[70] Wang K, Sun W, Salager S, Na SH, Khaddour G. Identifying material parameters for a micro-polar plasticity model via X-ray micro-ct images: lessons learned from the curve-fitting exercises. Int J Multiscale Comput Eng 2016.

[71] Hampel A, Schulze O, Heemann U, Zetsche F, Günther R, Salzer K, et al. Bmbfverbundvorhaben: Die modellierung des mechanischen verhaltens von steinsalz: Vergleich aktueller stoffgesetze und vorgehensweisensynthesebericht. FZK-PTKA, Karlsruhe; 2007. 